\title{
An 8-Week Freeze-Dried Blueberry Supplement Impacts Immune-Related Pathways: A Randomized, Double-Blind Placebo-Controlled Trial
}

\author{
Michèle Rousseau \\ Université Laval: Universite Laval \\ Justine Horne \\ Université Laval: Universite Laval \\ Frédéric Guénard \\ Université Laval: Universite Laval \\ Juan de Toro-Martín \\ Université Laval: Universite Laval \\ Véronique Garneau \\ Université Laval: Universite Laval \\ Valérie Guay \\ Université Laval: Universite Laval \\ Michèle Kearney \\ Université Laval: Universite Laval \\ Geneviève Pilon \\ Université Laval: Universite Laval \\ Denis Roy \\ Université Laval: Universite Laval

\section{Patrick Couture} \\ Université Laval: Universite Laval \\ Charles Couillard \\ Université Laval: Universite Laval

\section{André Marette} \\ Université Laval: Universite Laval \\ Marie-Claude Vohl ( $\nabla$ marie-claude.vohl@fsaa.ulaval.ca ) \\ Laval University https://orcid.org/0000-0002-7017-5848
}

\section{Research}

Keywords: Metabolic syndrome, blueberry, overweight/obesity, nutrition, immunity, transcriptomics, metabolomics, gene expression

Posted Date: September 24th, 2020

DOI: https://doi.org/10.21203/rs.3.rs-78859/v1 
License: @ (1) This work is licensed under a Creative Commons Attribution 4.0 International License. Read Full License 


\section{Abstract}

Background: Blueberries contain high level of polyphenolic compounds with high in vitro antioxidant capacities. Their consumption has been associated with improved vascular and metabolic health.

Purpose: The objective was to examine the effects of blueberry supplement consumption on metabolic syndrome (MetS) parameters and potential underlying mechanisms of action.

Methods: A randomized double-blind placebo-controlled intervention trial was conducted in adults at risk of developing MetS. Participants consumed $50 \mathrm{~g}$ daily of either a freeze-dried highbush blueberry powder (BBP) or a placebo powder for 8 weeks $(n=49)$. MetS phenotypes were assessed at week 0,4 and 8 . Fasting blood gene expression profiles and plasma metabolomic profiles were examined at baseline and week 8 to assess metabolic changes occurring in response to the BBP. A per-protocol analysis was used.

Results: Interaction effects were non-significant demonstrating that compared to the placebo, BBP had no statistically significant effect on body weight, blood pressure, fasting plasma lipid, insulin and glucose levels, insulin resistance (or sensitivity) and on glycated hemoglobin concentrations. However, there were significant within- and between-group differences including increased insulin resistance in the placebo group only, greater TG at week 4 in the BBP compared to placebo group and increased fasting insulin from week 4 to 8 in both groups. Moreover, there were significant changes in the expression of 49 genes and 35 metabolites following BBP consumption. Differentially regulated genes were clustered in immune-related pathways.

Conclusion: An 8-week BBP intervention did not significantly improve traditional markers of cardiometabolic health in adults at risk of developing MetS. However, metabolically relevant changes in gene expression and metabolites suggest that clinically significant cardiometabolic changes could take longer than 8 weeks to present and/or could result from whole blueberry consumption or a higher dosage. BBP may also have an effect on factors such as immunity even within a shorter 8-week timeframe.

Clinical trial registration: clinicaltrials.gov, NCT03266055, 2017, https://clinicaltrials.gov/ct2/show/NCT03266055? term=blueberry+vohl\&draw=2\&rank=1

\section{Introduction}

With an estimated prevalence of almost 35\% in the United States (1) and 19\% in Canada (2), metabolic syndrome (MetS) is a condition of great concern in developed countries. By clustering abdominal obesity, insulin resistance (IR), dyslipidemia and hypertension, people with MetS are at higher risk of developing type 2 diabetes and cardiovascular disease (3). Oxidative stress is a commonality for these risk factors and is suspected of playing a pro-inflammatory role thus promoting their development (4). Oxidative stress occurs when the body's antioxidant defenses are not sufficient to counterbalance production of free radicals and other reactive oxygen species (ROS) (4). Free radicals are highly reactive and have the potential to damage essential biomolecules including lipids, proteins and DNA, which in turn impair their functions (5). Notably, excess calorie intake leads to increased ROS production, which could eventually generate a pro-oxidant environment susceptible to cause cellular dysfunction promoting obesity-related diseases (4).

Nutrition has the potential to help mitigate issues related to increased ROS production. For example, many fruits are naturally rich in polyphenolic molecules with potent antioxidant and anti-inflammatory activity, which are part of their natural defense system against pathogens, environmental fluctuations and pro-oxidant stressors such as ultraviolet 
light (6). Berries are among fruits with the highest polyphenol content, mainly anthocyanins, resulting in their bright color (7-9). Compared to 25 other commonly eaten fruits, wild and cultivated blueberries were previously ranked first and fifth for their total phenolic content (respectively 429 and 285 gallic acid equivalent per $100 \mathrm{~g}$ of fruit) (9). Analyses of the effect of lowbush blueberry plant extracts on cultured cells also revealed insulin- and glitazone-like activities, suggesting that blueberries may possess antidiabetic properties $(8,10)$. Blueberry supplementation has previously been associated with favorable effects on blood pressure $(11,12)$, some aspects of brain cognitive function $(13,14)$ and plasma biomarkers of oxidative stress and inflammation (11). Blueberry consumption has also been demonstrated to be protective against the risk of myocardial infarction (15) and diabetes (16). However, these results are inconsistent in the literature, with some clinical trials showing no improvement on lipid profile $(11,17-19)$, insulin resistance $(11,18,20)$ or blood pressure $(17-20)$. Differences in study designs and populations tested (21) could explain these equivocal results, highlighting the need for further research on blueberry health properties. In addition, inter-individual variability in cardiometabolic responses to nutrition intervention is observed and can be partly attributable to genetic variations (22). In order to inform future investigations specific to blueberries and polyphenols as they relate to MetS, a better understanding of the physiological mechanism of action for blueberries (polyphenols) on MetS phenotypes is needed.

Accordingly, this 8-week parallel, randomized (1:1) double-blind placebo-controlled clinical trial of adults at risk of MetS had two overarching purposes. First, the study aimed to evaluate the impact of highbush blueberry powder (BBP) on the following MetS parameters: plasma insulin resistance (HOMA-IR) and sensitivity (Matsuda index), plasma lipids, arterial blood pressure, blood glucose, weight, body mass index (BMI) and waist circumference. Second, the study aimed to delineate the mechanism of action of highbush BBP on MetS parameters in overweight/obese adults through analyses of changes in key molecular signalling pathways and metabolic regulatory networks identified using analyses of transcriptomics and metabolomics. It was hypothesized that BBP have a significant effect on cardiometabolic MetS phenotypes and pathways over an 8-week follow-up period.

\section{Methods}

\section{STUDY POPULATION}

Recruitment of study participants was held between September 2017 and November 2018 in the greater Québec City metropolitan area, with follow-up occurring between October 10, 2017 and January 14, 2019. All recruitment and intervention visits took place at the Institute of Nutrition and Functional Foods (INAF), Université Laval. Recruitment ended when the sample size was achieved. Using group electronic messages sent to university and INAF members as well as newspapers and social media advertisements, a total of 657 individuals contacted the researchers for information on this study. Overall, 110 individuals met email or phone pre-screening criteria and were scheduled for a screening visit at the clinical investigation unit of INAF. Before each visit, participants were asked to follow a 12-h overnight fast and abstinence from alcohol for $48 \mathrm{~h}$. They were also asked to avoid vigorous exercise for $24 \mathrm{~h}$ prior the visit. Inclusion criteria were as follows: Caucasian men or premenopausal, non-pregnant and non-lactating Caucasian women in good health, having a BMI between 25 and $40 \mathrm{~kg} / \mathrm{m}^{2}$ or a waist circumference $\geq 94 \mathrm{~cm}$ for men and $\geq$ $80 \mathrm{~cm}$ for women. All participants had to have at least one of the following: fasting plasma triglycerides (TG) $\geq 1.35 \mathrm{mmol} / \mathrm{L}$ or fasting insulin concentration $\geq 42 \mathrm{pmol} / \mathrm{L}$ using our new analytic method and corresponding to a threshold value of $60 \mathrm{pmol} / \mathrm{L}$ with the former method that was predictive of a higher risk of cardiovascular disease in the Quebec population (23). Participants were excluded from the study if they were diagnosed with diabetes, hypercholesterolemia or hypertension; were allergic or intolerant to blueberries; had a taste aversion to blueberries; were taking medication affecting study parameters; had taken antibiotics, supplements or natural health products on a 
regular basis over the past 3 months, had undergone surgery in the last 3 months or had planned surgery during the duration of the study; were nicotine users; followed unique dietary patterns (such as a vegan, gluten-free or ketogenic diet); had lost or gained $>5 \%$ of their body weight in the last 3 months; or were having more than 2 alcoholic drinks per day on a regular basis. Participants also had to be willing to commit to the study instructions from the run-in period until the end of the intervention. These instructions were to eat a maximum of 2 portions of berries weekly (including whole fruits, juice, jam and desert but excluding the placebo/blueberry powders); $140 \mathrm{~g}$ of food containing cocoa weekly; 1 cup of tea or 4 cups of coffee daily; and 2 alcoholic drinks per week. Red wine and port were prohibited due to their flavonoid content. Participants were also asked to report the use of new medications and to avoid natural health product consumption or changes in lifestyle habits. The inclusion/exclusion criteria were adjusted following the commencement of the trial; the criteria listed above reflect the revised, most current criteria. There were no other changes to the methods or outcomes after the trial commenced. This study was approved by the Ethics Committee of Université Laval and registered at https://clinicaltrials.gov/ (NCT03266055). All subjects signed a written informed consent prior their participation to the study.

\section{STUDY PROTOCOL AND INTERVENTION}

This study is a randomized double-blind placebo-controlled clinical intervention. Sex-stratified block randomization was applied electronically on the INAF electronic management platform to ensure a 1:1 treatment ratio for each sex to either blueberry (BBP) or placebo powder. Powders were both provided by the US Highbush Blueberry Council. The BBP consisted of a blend of milled freeze-dried highbush blueberries from two cultivars (Vaccinium virgatum (ashei) and Vaccinium corymbosum), in a 1:1 ratio. The placebo powder was isocaloric and of similar aspect and taste as the BBP, but contained a mixture of dextrose, maltodextrin, fructose, citric acid, malic acid, natural and artificial flavor, xanthan gum, silicon dioxide, and FD\&C Red 40 and Blue 2 lakes. Both powders were packaged in identical aluminum packets identified with the letters A or B (for blinding) by the US Highbush Blueberry Council before sending packets to the study centre. Sufficient powder packets were provided at each visit to participants. They had to take a total of $50 \mathrm{~g}$ of powder daily divided in two packets of $25 \mathrm{~g}$ each, taken at least 8 hours apart. Fifty $\mathrm{g}$ of freeze-dried BBP is equivalent to about $350 \mathrm{~g}$ ( 2 and 1/3 cups) of fresh blueberries. Participants were asked to dilute the content of each packet in $300 \mathrm{ml}$ water in a plastic cup provided by the study coordinator or to mix it into foods that were already part of their usual diet such as breakfast cereals, milk, yogurt or smoothies. They were asked not to heat the powder or add it to a hot liquid or food. To assess possible adverse events, participants completed a self-administered side effects questionnaire at weeks 4 and 8 . Changes in plasma insulin, glucose, lipids and lipoproteins were primary outcomes. Changes in gene expression, metabolites, and blood pressure were secondary outcomes. All other analyses were exploratory.

When eligibility was confirmed, participants were enrolled in the intervention and invited to the research institute for the baseline visit (week - 2) prior to a 2-week run-in period (Fig. 1). In that period, participants had to commit to the abovementioned study directives without taking the powder. At the start of the intervention (week 0 ), participants were randomized to consume either the BBP or the placebo powder for 8 weeks and scheduled for visits at the research center at 4-week intervals (week 4 and 8). The randomization list was created by VGa. Clinical coordinators (VGa, MK, VGu) were responsible for enrolling participants and assigning them to interventions. Compliance to study protocol and supplementation was documented by the completion of a journal and by returning all powder packets (both empty and remaining) at each visit.

\section{DIETARY ASSESSMENT AND QUESTIONNAIRES}

Dietary habits were assessed on weeks 0,4 and 8 by a web-based, self-administered, past-month food frequency questionnaire (FFQ). This FFQ was previously validated for French-speaking Canadian adults (24). Briefly, participants 
were asked to report their consumption of 136 items grouped in 8 categories including dairy products, fruits, vegetables, meat and alternatives, cereals and grain products, beverages, "other foods" and supplements. Powders' nutritional values were added to intakes reported on the FFQs completed at week 4 and week 8 with consideration of individual compliance percentage. Women and men with intakes lower than 600 or 800 kcal per day or greater than 3500 or $4200 \mathrm{kcal} /$ day, respectively, were considered as under- or over-reporters and as such, their dietary intakes were not included in the analyses (25). On the final visit, all participants completed a short questionnaire about the powders' taste acceptability and consumption.

\section{ANTHROPOMETRIC MEASURES}

Weight was measured using a BWB-800 electronic scale (Tanita, Arlington Heights, IL) to the nearest $0.1 \mathrm{~kg}$ with patients wearing light indoor clothes and no shoes. Height and waist circumference was measured to the nearest millimeter according to procedures recommended at the Airlie conference (26): waist was defined as the midpoint between the last floating rib and the top of the iliac crest. The mean of three consecutive measures was used for analyses. Systolic (SBP) and diastolic (DBP) blood pressure were measured while sitting on a chair after a 10-minute rest. Again, the mean of three measures repeated at 3-minute intervals was used for analyses.

\section{MetS PHENOTYPE PARAMETERS}

Blood samples were drawn at each visit. Fasting plasma lipid profile (total-cholesterol (Total-C), HDL-cholesterol (HDLC), LDL-cholesterol (LDL-C) and triglyceride (TG), glucose, insulin and glycated hemoglobin (HbA1c) concentrations were measured at the Centre Hospitalier Universitaire de Québec (CHUQ)-Université Laval. Total-C, HDL-C, TG and glucose were measured by enzyme-based assays. LDL-C was calculated with the Friedewald formula (27) and insulin was assessed by chemiluminescence. HbA1c was measured by ion-exchange high performance liquid chromatography.

Participants underwent oral glucose tolerance tests (OGTT) at the beginning (week 0) and at the end (week 8) of the supplementation period. Values for the fasting blood samples were calculated as the mean of times - 15 and 0 minute before participants were asked to drink a 75-g glucose solution. Blood was further drawn at 15, 30, 60, 90 and 120 minutes after glucose solution intake. The homeostatic model assessment of insulin resistance (HOMA-IR) was computed as fasting glucose and fasting insulin product divided by the normalizing factor 22.5 (28). Matsuda index (29) was calculated as 10,000 divided by square root of (fasting glucose*fasting insulin)*(mean glucose*mean insulin), with mean glucose and insulin concentrations being calculated as the mean of fasting, 30, 60, 90 and 120 min samples. Units of measurement were converted in order to comply with the units used for these equations. Due to high hemolysis in some blood samples, Matsuda index has been calculated for only a limited number of subjects in each group.

\section{Statistical Analysis (MetS Phenotype Parameters)}

SAS studio version 9.4 (SAS Institute, Cary, NC) was used for statistical analyses, which were by originally assigned groups. Each variable was assessed for normality using skewness and kurtosis. Non-normally distributed variables that have been transformed prior statistical analyses are indicated in notes below each table. Descriptive characteristics are presented as means with standard deviations (SD) or ranges. An analysis of variance was used to test for differences in dietary intakes and indices of cardiometabolic health including HOMA-IR and Matsuda index using the MIXED procedure in SAS with compound symmetry as covariance structure. Treatment, time and treatment*time interaction were considered as fixed effects with repeated measurements. Pairwise comparisons among groups were performed using least square means (LS-means) when a significant effect $(p<0.05)$ was 
observed. Analyses were performed with and without adjustments for covariates including age, sex and BMI and/or nutrient intakes. The model was adjusted for values at week 0 of each individual variable. Delta change were compared between groups using general linear models. A per-protocol analysis was used. P-values $<0.05$ were considered significant.

\section{TRANSCRIPTOMICS}

Blood cell gene expression profiles were examined to assess nutrition-related metabolic changes occurring in response to the BBP. Blood samples were collected in PAXgene blood RNA tubes (Qiagen, Valencia, CA, USA) at week 0 and week 8 , and were stored at $-80^{\circ} \mathrm{C}$ until the analyses. Total RNA was extracted and samples were sent to the McGill University and Génome Québec Innovation Centre for sequencing. The quality of RNA samples was evaluated with the 2100 Bioanalyzer (Agilent, Santa Clara, CA, US). RNA samples were converted to cDNA with the Illumina NEB stranded mRNA library preparation kit (Illumina, San Diego, CA, US; rRNA-depleted stranded (HMR)) for sequence library preparation based on the manufacturer's protocol. Final libraries were sequenced on an Illumina NovaSeq6000 S4 sequencer using paired-end, 100 bp reads. For bioinformatic analyses, raw reads were trimmed for length $(n=50)$, quality (phred33 score > = 30) and adaptor sequence using Trim Galore (v0.6.5), a wrapper tool around Cutadapt (v1.15) and FastQC (v0.11.9). Raw read counts and normalized read counts (in transcript per million, TPM) were obtained using the Kallisto quant command (v0.46.2) using default parameters with 100 bootstraps and were aligned

to the GRCh38 human reference transcriptome (30). Data pre-processing and automatic transcript filtering, based on a worthwhile number of counts in a minimum number of samples were performed with sleuth v0.3 and edgeR v3.28.1, respectively, both implemented in R v3.6.3 (31). Given the paired nature of our samples, differential transcript expression across the BBP group from week 0 to week 8 was determined using a generalization of a paired t-test implemented in the quasi-likelihood framework of edgeR. Differentially expressed transcripts between post- vs. preintervention with BBP were considered at a false-discovery rate (FDR)-corrected $p$-value $<0.05$. The functional significance of genes showing at least a $25 \%$ difference (1.25-fold change) between pre- and post-supplementation states was explored by pathway enrichment analysis using the clusterProfiler v3.16.0 R package (32). ClusterProfiler implements statistical methods to analyze and visualize functional profiles of genes/gene clusters and produces adjusted $\mathrm{p}$-values using the Benjamini-Hochberg procedure $(\mathrm{BH}-\mathrm{p})$ for significantly enriched pathways. The following pathway databases were used for functional enrichment analysis: Gene Ontology Biological Processes (GO-BP), Reactome and the Kyoto Encyclopedia of Genes and Genomes (KEGG). The cnetplot function implemented in the clusterProfiler package was used to visualize significantly enriched pathways.

\section{METABOLOMICS}

Plasma samples collected at week 0 and 8 were sent to the Analytical Facility for Bioactive Molecules at the Hospital for Sick Children in Toronto, Canada. The quantitative analysis of 630 metabolites from 26 biochemical classes was performed in paired blood samples from 24 participants before and after the BBP supplementation with the MxP® Quant 500 kit for targeted metabolic profiling (Biocrates Life Sciences AG, Innsbruck, Austria).

\section{Statistical Analysis (Metabolomics)}

Metabolite data from 24 participants (pre- versus post-intervention with BBP) were processed using the MetaboAnalystR package (v3.0) (33). First, 113 metabolites with a constant or single value across samples were found and deleted. Non-informative signals were further filtered out based on the interquartile range estimate and samples were normalized by quantile normalization. Metabolite data were log-transformed and scaled by Pareto scaling (mean-centered and divided by the square root of the standard deviation of each variable). After quantile normalization, one additional metabolite with a constant value was found and deleted. From the original 630 metabolites analyzed, a total of 386 were included in the final statistical analysis. Paired t-tests were used to analyze 
within-subject changes in blood metabolite levels between pre- and post-supplementation states. A volcano plot associated to paired t-tests was further used to visualize the most differential metabolite changes between pre- and post-supplementation. A p-value $<0.05$, along with a count of significant pairs higher than $50 \%$ showing at least $25 \%$ difference (1.25-fold change), were the criteria used to consider metabolite blood levels to significantly differ between pre- and post-supplementation.

\section{Dimensional Reduction}

Dimensional reduction was conducted using the partial least squares discriminant analysis (PLS-DA), a supervised algorithm able to reduce the number of metabolites in high-dimensional metabolomics data to produce robust and easy-to-interpret models. This method is able to differentiate the class membership through multivariate regression of a given set of metabolites. In the present study, we used a variation of PLS-DA, the multilevel PLS-DA (mPLS-DA), given its ability to exploit the paired structure of the multivariate data obtained before and after the BBP supplementation in the same group of participants $(34,35)$. A sparse mPLS-DA (smPLS-DA) was used to identify the most important metabolites that help discriminate matched study groups (36). The smPLS-DA algorithm was implemented using the mixOmics R package (v6.12.1) (37). The variable importance in projection (VIP) coefficients were computed as a weighted sum of squares of the smPLS-DA loadings to depict the relative importance of each metabolite in the classification model. Predictors with large VIP are the most relevant for discriminating class membership (37).

\section{Results}

\section{PARTICIPANTS CHARACTERISTICS AND ADHERENCE}

Of the 110 individuals screened for eligibility, 59 participants were included in this randomized double-blind, placebocontrolled intervention trial, with analyses conducted on a final sample of 49 individuals who consumed the BBP $(n=$ 25 ) or the placebo powder $(n=24)$ (Fig. 2). Characteristics of participants at week 0 who completed the study protocol are presented in Table 1. Participants were adults between the ages of 22 and 53 with dietary intakes of approximately $2000 \mathrm{kcal} /$ day and slightly deteriorated cardiometabolic risk profile (Table 2 and Table 3). Adherence to the study protocol was robust, with an overall powder intake compliance rate of $92.7 \pm 7.5 \%$ and no significant differences between groups (BBP: $92.4 \pm 7.7 \%$ and placebo: $92.9 \pm 7.3 \%$ ). Results from the side effects questionnaire indicated that participants experienced some minor side effects with both the BBP and placebo powder (Supplementary Fig. 1), but these side effects were generally tolerable with only one participant dropping out of the study as a result of persistent abdominal discomfort. 
Table 1

General baseline characteristics of participants

\begin{tabular}{|c|c|c|c|}
\hline & All subjects $(n=49)$ & $\mathrm{BBP}(n=25)$ & Placebo $(n=24)$ \\
\hline Weight (kg) & $91.5[62.5-130.4]$ & 89.6 [62.5-126.5] & $93.6[71.6-130.4]$ \\
\hline Height (cm) & $171.0[152.5-190.3]$ & 170.8 [152.5-187.8] & $171.3[156.0-190.3]$ \\
\hline $\mathrm{BMI}\left(\mathrm{kg} / \mathrm{m}^{2}\right)$ & $31.3[23.4-47.1]$ & $30.8[23.4-47.1]$ & 31.8 [25.7-39.7] \\
\hline Waist circ. (cm) & $104.1[81.0-131.3]$ & $101.7[81.0-131.3]$ & $106.6[82.6-127.2]$ \\
\hline Hip circ. (cm) & $111.8[92.2-141.8]$ & $110.0[92.2-141.8]$ & $113.6[99.8-132.9]$ \\
\hline $\mathrm{SBP}(\mathrm{mmHg})$ & 115 [94-134] & $115[99-132]$ & 114 [94-134] \\
\hline $\mathrm{DBP}(\mathrm{mmHg})$ & $72[52-91]$ & $72[57-82]$ & 72 [52-91] \\
\hline Total-C (mmol/L) & $4.40[2.56-6.49]$ & $4.55[2.99-6.41]$ & $4.24[2.56-6.49]$ \\
\hline $\mathrm{TG}(\mathrm{mmol} / \mathrm{L})$ & $1.43[0.36-3.98]$ & $1.63[0.53-3.98]$ & $1.22[0.36-2.30]$ \\
\hline $\mathrm{HDL}-\mathrm{C}(\mathrm{mmol} / \mathrm{L})$ & $1.18[0.74-2.07]$ & $1.16[0.74-1.99]$ & $1.21[0.85-2.07]$ \\
\hline $\mathrm{LDL}-\mathrm{C}(\mathrm{mmol} / \mathrm{L})$ & $2.56[1.09-4.21]$ & $2.64[1.58-4.05]$ & $2.48[1.09-4.21]$ \\
\hline Total-C/HDL-C & $3.87[1.97-6.97]$ & $4.09[2.42-6.97]$ & $3.65[1.97-6.73]$ \\
\hline Fasting glucose $(\mathrm{mmol} / \mathrm{L})^{1}$ & $4.9[4.0-6.4]$ & $5.02[4.1-5.7]$ & $4.83[4.0-6.4]$ \\
\hline Fasting insulin (pmol/L) ${ }^{2}$ & $82[31-184]$ & 80.9 [31-184] & 82.4 [43-169] \\
\hline HbA1c (\%) & $0.051[0.045-0.058]$ & $0.051[0.045-0.056]$ & $0.051[0.045-0.058]$ \\
\hline Age (years) & $36.0[22-53]$ & $35.2[23-53]$ & $36.7[22-48]$ \\
\hline Sex [n (\% female)] & $27(55)$ & $13(52)$ & $14(58)$ \\
\hline Highest education level completed [n (\%)] & $4(8)$ & $3(12)$ & $1(4)$ \\
\hline High school & $16(33)$ & $6(24)$ & $10(42)$ \\
\hline College & $29(59)$ & $16(64)$ & $13(54)$ \\
\hline \multicolumn{4}{|l|}{ University } \\
\hline Occupation [n (\%)] & $10(20)$ & $7(28)$ & $3(13)$ \\
\hline Student (full-time) & $5(10)$ & $4(16)$ & $1(4)$ \\
\hline \multicolumn{4}{|l|}{ Student (part-time) } \\
\hline Annual household income $\$ \operatorname{CDN}^{3}[\mathrm{n}(\%)]$ & $10(21)$ & $7(29)$ & $3(13)$ \\
\hline 0-39 999 & $15(32)$ & $8(33)$ & $7(30)$ \\
\hline $40000-79000$ & $9(19)$ & $4(17)$ & $5(22)$ \\
\hline $80000-99000$ & $13(28)$ & $5(21)$ & $8(35)$ \\
\hline$\geq 100000$ & & & \\
\hline
\end{tabular}




\section{All subjects $(n=49)$ \\ $\operatorname{BBP}(n=25)$ \\ Placebo $(n=24)$}

Values from weight through to age are raw means [range].

${ }^{1} \mathrm{n}=48$ (24 for BBP and 24 for placebo)

${ }^{2} n=39$ (21 for BBP and 18 for placebo)

${ }^{3} n=47$ (24 for BBP and 23 for placebo)

Abbreviations: BMI: body mass index; Waist circ: waist circumference. Hip circ: hip circumference; SBP: systolic blood pressure; DBP: diastolic blood pressure; Total-C: total-cholesterol; TG: triglycerides; HDL-C: HDL-cholesterol; LDL-C: LDL-cholesterol; HbA1c: glycated hemoglobin; BBP: blueberry powder.

Table 2

Effects of treatment and/or time on nutritional intake

\begin{tabular}{|c|c|c|c|c|c|c|c|c|c|}
\hline \multirow{3}{*}{ Variable } & \multicolumn{2}{|c|}{ Week 0} & \multicolumn{2}{|c|}{ Week 4} & \multicolumn{2}{|c|}{ Week 8} & \multicolumn{3}{|l|}{ p-value ${ }^{1}$} \\
\hline & BBP & Placebo & BBP & Placebo & BBP & Placebo & Treatment & Time & Treatment* \\
\hline & & & & & & & & & Time \\
\hline Calories (kcal) & $\begin{array}{l}1979 \\
\pm 598\end{array}$ & $\begin{array}{l}2080 \pm \\
550\end{array}$ & $\begin{array}{l}2152 \\
\pm 553\end{array}$ & $\begin{array}{l}2165 \pm \\
479\end{array}$ & $\begin{array}{l}2204 \\
\pm 664\end{array}$ & $\begin{array}{l}2203 \pm \\
540\end{array}$ & 0.67 & 0.07 & 0.68 \\
\hline $\begin{array}{l}\text { Carbohydrates } \\
\text { (g) }\end{array}$ & $\begin{array}{l}226 \\
\pm \\
71^{m}\end{array}$ & $\begin{array}{l}242 \pm \\
63\end{array}$ & $\begin{array}{l}261 \\
\pm 60^{n}\end{array}$ & $\begin{array}{l}269 \pm \\
57^{m}\end{array}$ & $\begin{array}{l}269 \\
\pm 75^{n}\end{array}$ & $\begin{array}{l}279 \pm \\
65^{n}\end{array}$ & 0.42 & 0.0001 & 0.89 \\
\hline $\begin{array}{l}\text { Total sugars } \\
\text { (g) }\end{array}$ & $\begin{array}{l}94 \pm \\
30^{m}\end{array}$ & $\begin{array}{l}103 \pm \\
39^{m}\end{array}$ & $\begin{array}{l}116 \\
\pm 28^{n}\end{array}$ & $\begin{array}{l}122 \pm \\
38^{n}\end{array}$ & $\begin{array}{l}122 \\
\pm 39^{n}\end{array}$ & $\begin{array}{l}128 \pm \\
42^{n}\end{array}$ & 0.41 & < 0.0001 & 0.94 \\
\hline Fibre (g) & $\begin{array}{l}20 \pm \\
9^{m}\end{array}$ & $\begin{array}{l}24 \pm \\
10^{m}\end{array}$ & $\begin{array}{l}31 \pm \\
6^{n}\end{array}$ & $21 \pm 7^{n}$ & $\begin{array}{l}30 \pm \\
6^{n}\end{array}$ & $24 \pm 9$ & 0.08 & $\begin{array}{l}< \\
0.0001\end{array}$ & $<0.0001$ \\
\hline Total Fat (g) & $\begin{array}{l}85 \pm \\
31\end{array}$ & $87 \pm 30$ & $\begin{array}{l}88 \pm \\
30\end{array}$ & $84 \pm 27$ & $\begin{array}{l}87 \pm \\
33\end{array}$ & $86 \pm 28$ & 0.99 & 0.83 & 0.71 \\
\hline Proteins (g) & $\begin{array}{l}84 \pm \\
25\end{array}$ & $93 \pm 27$ & $\begin{array}{l}85 \pm \\
26\end{array}$ & $92 \pm 24$ & $\begin{array}{l}90 \pm \\
33\end{array}$ & $89 \pm 27$ & 0.37 & 0.83 & 0.12 \\
\hline Alcohol (g) & $3 \pm 3$ & $2 \pm 2$ & $3 \pm 2$ & $2 \pm 2$ & $3 \pm 3$ & $2 \pm 2$ & 0.15 & 0.65 & 0.35 \\
\hline $\begin{array}{l}\text { Vitamin C } \\
(\mathrm{mg})\end{array}$ & $\begin{array}{l}96 \pm \\
38\end{array}$ & $\begin{array}{l}118 \pm \\
60\end{array}$ & $\begin{array}{l}96 \pm \\
25\end{array}$ & $98 \pm 34$ & $\begin{array}{l}95 \pm \\
28\end{array}$ & $\begin{array}{l}112 \pm \\
49\end{array}$ & 0.36 & 0.62 & 0.23 \\
\hline \multicolumn{10}{|c|}{$\begin{array}{l}\text { Values are mean } \pm \text { SD. } 1 \text {. Unadjusted } p \text {-value. Analyses were conducted using the MIXED procedure with SAS } \\
\text { studio v.3.8. Vitamin } \mathrm{C} \text { was } \log _{10} \text { transformed. Significant } p \text {-values are in bold. LSMEANS pairwise comparisons } \\
\text { were performed only when the main factor effect was considered statistically significant }(p<0.05) \text {. Results that do } \\
\text { not share the same letter }(m, n, 0) \text { are significantly different }(p<0.05) \text { from each other. BBP: } n=24 \text { (week } 0) \text { and } 23 \\
\text { ( } 4 \text { and } 8 \text { weeks); Placebo: } n=22 \text { (week } 0 \text { ) and } 23 \text { ( } 4 \text { and } 8 \text { weeks). }\end{array}$} \\
\hline \multicolumn{10}{|c|}{ Abbreviations: BBP: blueberry powder. } \\
\hline
\end{tabular}


Table 3

Indices of cardiometabolic health over time by intervention group

\begin{tabular}{|c|c|c|c|c|c|c|c|c|c|}
\hline & \multicolumn{2}{|l|}{ Week 0} & \multicolumn{2}{|l|}{ Week 4} & \multicolumn{2}{|l|}{ Week 8} & \multicolumn{3}{|l|}{$p$-values } \\
\hline & BBP & Placebo & BBP & Placebo & BBP & Placebo & Treatment & Time & Treatment \\
\hline & & & & & & & & & *Time \\
\hline & $\mathrm{n}=25$ & $\mathrm{n}=24$ & $\mathrm{n}=25$ & $\mathrm{n}=24$ & $\mathrm{n}=25$ & $n=24$ & & & \\
\hline Weight (kg) & $\begin{array}{l}89.6 \pm \\
17.7^{a}\end{array}$ & $\begin{array}{l}93.6 \pm \\
15.3\end{array}$ & $\begin{array}{l}90.3 \pm \\
18.1^{\mathrm{b}}\end{array}$ & $\begin{array}{l}93.8 \pm \\
15.4\end{array}$ & $\begin{array}{l}90.1 \pm \\
18.1^{b}\end{array}$ & $\begin{array}{l}93.8 \pm \\
15.4\end{array}$ & 0.44 & 0.007 & 0.39 \\
\hline $\begin{array}{l}\text { BMI } \\
\left(\mathrm{kg} / \mathrm{m}^{2}\right)\end{array}$ & $\begin{array}{l}30.8 \pm \\
6.2^{\mathrm{a}}\end{array}$ & $\begin{array}{l}31.8 \pm \\
3.8\end{array}$ & $\begin{array}{l}31.0 \pm \\
6.3^{b}\end{array}$ & $\begin{array}{l}31.9 \pm \\
3.9\end{array}$ & $\begin{array}{l}30.9 \pm \\
6.3^{b}\end{array}$ & $\begin{array}{l}31.9 \pm \\
3.8\end{array}$ & 0.36 & 0.02 & 0.47 \\
\hline $\begin{array}{l}\text { Waist circ } \\
\text { (cm) }\end{array}$ & $\begin{array}{l}101.7 \\
\pm 13.3\end{array}$ & $\begin{array}{l}106.6 \pm \\
10.4\end{array}$ & $\begin{array}{l}102.0 \\
\pm 14.5\end{array}$ & $\begin{array}{l}106.5 \pm \\
10.9\end{array}$ & $\begin{array}{l}101.5 \\
\pm 14.4\end{array}$ & $\begin{array}{l}107.0 \pm \\
11.1\end{array}$ & 0.17 & 0.95 & 0.26 \\
\hline $\begin{array}{l}\text { SBP } \\
(\mathrm{mmHg})\end{array}$ & $\begin{array}{l}115 \pm \\
9\end{array}$ & $\begin{array}{l}114 \pm \\
10\end{array}$ & $\begin{array}{l}115 \pm \\
8\end{array}$ & $\begin{array}{l}113 \pm \\
13\end{array}$ & $\begin{array}{l}114 \pm \\
8\end{array}$ & $\begin{array}{l}114 \pm \\
13\end{array}$ & 0.74 & 0.87 & 0.69 \\
\hline $\begin{array}{l}\text { DBP } \\
(\mathrm{mmHg})\end{array}$ & $72 \pm 7$ & $72 \pm 10$ & $73 \pm 7$ & $70 \pm 9$ & $73 \pm 7$ & $73 \pm 9$ & 0.59 & 0.55 & 0.33 \\
\hline $\begin{array}{l}\text { Total-C } \\
(\mathrm{mmol} / \mathrm{L})\end{array}$ & $\begin{array}{l}4.55 \pm \\
1.03\end{array}$ & $\begin{array}{l}4.24 \pm \\
0.88\end{array}$ & $\begin{array}{l}4.65 \pm \\
1.02\end{array}$ & $\begin{array}{l}4.39 \pm \\
0.92\end{array}$ & $\begin{array}{l}4.57 \pm \\
0.97\end{array}$ & $\begin{array}{l}4.32 \pm \\
0.82\end{array}$ & 0.30 & 0.22 & 0.91 \\
\hline $\begin{array}{l}\text { TG } \\
(\mathrm{mmol} / \mathrm{L})\end{array}$ & $\begin{array}{l}1.63 \pm \\
0.96\end{array}$ & $\begin{array}{l}1.22 \pm \\
0.41\end{array}$ & $\begin{array}{l}1.85 \pm \\
0.96^{y}\end{array}$ & $\begin{array}{l}1.30 \pm \\
0.65^{z}\end{array}$ & $\begin{array}{l}1.74 \pm \\
0.77\end{array}$ & $\begin{array}{l}1.35 \pm \\
0.42\end{array}$ & 0.02 & 0.10 & 0.45 \\
\hline $\begin{array}{l}\mathrm{HDL}-\mathrm{C} \\
(\mathrm{mmol} / \mathrm{L})\end{array}$ & $\begin{array}{l}1.16 \pm \\
0.29\end{array}$ & $\begin{array}{l}1.21 \pm \\
0.28\end{array}$ & $\begin{array}{l}1.16 \pm \\
0.32\end{array}$ & $\begin{array}{l}1.27 \pm \\
0.30\end{array}$ & $\begin{array}{l}1.15 \pm \\
0.33\end{array}$ & $\begin{array}{l}1.20 \pm \\
0.24\end{array}$ & 0.18 & 0.08 & 0.19 \\
\hline $\begin{array}{l}\text { LDL-C } \\
(\mathrm{mmol} / \mathrm{L})\end{array}$ & $\begin{array}{l}2.64 \pm \\
0.81\end{array}$ & $\begin{array}{l}2.48 \pm \\
0.80\end{array}$ & $\begin{array}{l}2.63 \pm \\
0.70\end{array}$ & $\begin{array}{l}2.52 \pm \\
0.81\end{array}$ & $\begin{array}{l}2.63 \pm \\
0.80\end{array}$ & $\begin{array}{l}2.51 \pm \\
0.69\end{array}$ & 0.54 & 0.93 & 0.89 \\
\hline $\begin{array}{l}\text { Fasting } \\
\text { glucose } \\
(\mathrm{mmol} / \mathrm{L})^{1}\end{array}$ & $\begin{array}{l}5.02 \pm \\
0.43\end{array}$ & $\begin{array}{l}4.83 \pm \\
0.43\end{array}$ & $\begin{array}{l}5.16 \pm \\
0.43\end{array}$ & $\begin{array}{l}4.95 \pm \\
0.50\end{array}$ & $\begin{array}{l}5.03 \pm \\
0.31\end{array}$ & $\begin{array}{l}4.94 \pm \\
0.48\end{array}$ & 0.13 & 0.04 & 0.40 \\
\hline $\begin{array}{l}\text { Fasting } \\
\text { insulin } \\
(\mathrm{pmol} / \mathrm{L})^{2}\end{array}$ & $\begin{array}{l}80.9 \pm \\
33.4^{a, b}\end{array}$ & $\begin{array}{l}82.4 \pm \\
36.5^{a, b}\end{array}$ & $\begin{array}{l}87.5 \pm \\
66.7^{a}\end{array}$ & $\begin{array}{l}81.0 \pm \\
44.6^{a}\end{array}$ & $\begin{array}{l}96.7^{ \pm} \\
47.8^{b}\end{array}$ & $\begin{array}{l}95.9^{ \pm} \\
44.5^{\mathrm{b}}\end{array}$ & 0.73 & 0.02 & 0.92 \\
\hline $\mathrm{HbA} 1 \mathrm{C}(\%)^{3}$ & $\begin{array}{l}0.051 \\
\pm \\
0.003\end{array}$ & $\begin{array}{l}0.051 \pm \\
0.003\end{array}$ & $\begin{array}{l}0.052 \\
\pm \\
0.003\end{array}$ & $\begin{array}{l}0.050 \pm \\
0.002\end{array}$ & $\begin{array}{l}0.052 \\
\pm \\
0.003\end{array}$ & $\begin{array}{l}0.051 \pm \\
0.003\end{array}$ & 0.17 & 0.14 & 0.67 \\
\hline
\end{tabular}




\section{Week 0 \\ Week 4 \\ Week 8 \\ p-values}

Results are presented as raw means \pm SD. Analyses were conducted using the MIXED procedure with SAS studio v.3.8. Significant $p$-values are in bold. LSMEANS post hoc pairwise comparisons were performed only when the main factor effect was considered statistically significant $(p<0.05)$. Results that do not share the same letter $(a, b, c$ for time effect and $y, z$ for treatment effect) are significantly different $(p<0.05)$ from each other. The following nonnormally distributed variables were $\log _{10}$ transformed: BMI and fasting insulin. HDL-C was inverse transformed.

1. BBP: $n=24$ (week 0), $n=25$ (week 4 and 8); Placebo: $n=24$ (week 0 and 4), $n=23$ (week 8)

2. BBP: $n=21$ (week 0), $n=24$ (week 4), $n=22$ (week 8); Placebo $n=18$ (week 0), n= 24 (week 4), $n=20$ (week 8)

3. BBP: $n=25$ (week 0 and 8), $n=24$ (week 4); Placebo $n=24$ (week 0, 4 and 8)

Abbreviations: BMI: body mass index; Waist circ: waist circumference; SBP: systolic blood pressure; DBP: diastolic blood pressure; Total-C: total cholesterol; TG: triglycerides; HDL-L: HDL-cholesterol; LDL-C: LDL-cholesterol; HbA1c: glycated hemoglobin; BBP: blueberry powder.

\section{DIETARY INTAKE}

As presented in Table 2, there were no significant between-group differences, within-group changes or treatment*time interactions for the nutrients analyzed other than carbohydrates, total sugars, and fibre. The significant results for these three nutrients relate to the nutritional breakdown of the BBP and placebo powder, which are comprised of similar quantities of carbohydrates and total sugar with a higher fibre content in the BBP compared to the placebo powder (Supplementary Table 1); thus, these results relate to the compliance to the intervention protocols. Specifically, carbohydrate intake increased significantly from week 0 to weeks 4 and to 8 in the BBP group, and from week 4 to 8 in the placebo powder group. Total sugar increased significantly from week 0 to weeks 4 and 8 in both the BBP and placebo group. Fibre increased significantly from week 0 to weeks 4 and 8 in the BBP group, and decreased from week 0 to 4 for the placebo group. There was a significant treatment*time interaction for fibre whereby the BBP group had significantly greater changes (increases) in fibre intake compared to the placebo group from week 0 to weeks 4 and 8 .

\section{MetS PHENOTYPES}

The independent effects of treatment and time, as well as their interactions, on changes in cardiometabolic risk factors are presented in Table 3. Before adjusting for potential confounders, there were statistically significant changes (increases) in weight and BMI from week 0 to weeks 4 and 8 in the BBP group only, but these changes were not clinically meaningful. There were also significant within-group changes for fasting insulin and glucose levels. However, the post-hoc analysis revealed no significant changes for fasting glucose. For fasting insulin, there were significant differences in both the BBP and placebo groups between week 4 and week 8 . At week 4, TG were significantly higher in the BBP group compared to the placebo group. Results remained unchanged after adjusting for age, sex, BMI (for blood pressure and biochemical markers), and baseline values, except for TG which was no longer significant (data not shown). These results were no longer significant after adjusting for calories, fibre or total sugar intake, individually, therefore suggesting that the addition of calories, fibre or total sugar from the interventions contributed to the results (data not shown). Treatment^time interactions were all non-significant.

Changes from week 0 to week 8 in plasma concentrations of cardiometabolic risk factors were also investigated. As presented in Table 4, changes were not significantly different between groups either in the unadjusted or the age, sex and BMI-adjusted models. 
Table 4

Effect of treatment on changes in cardiometabolic variables of interest

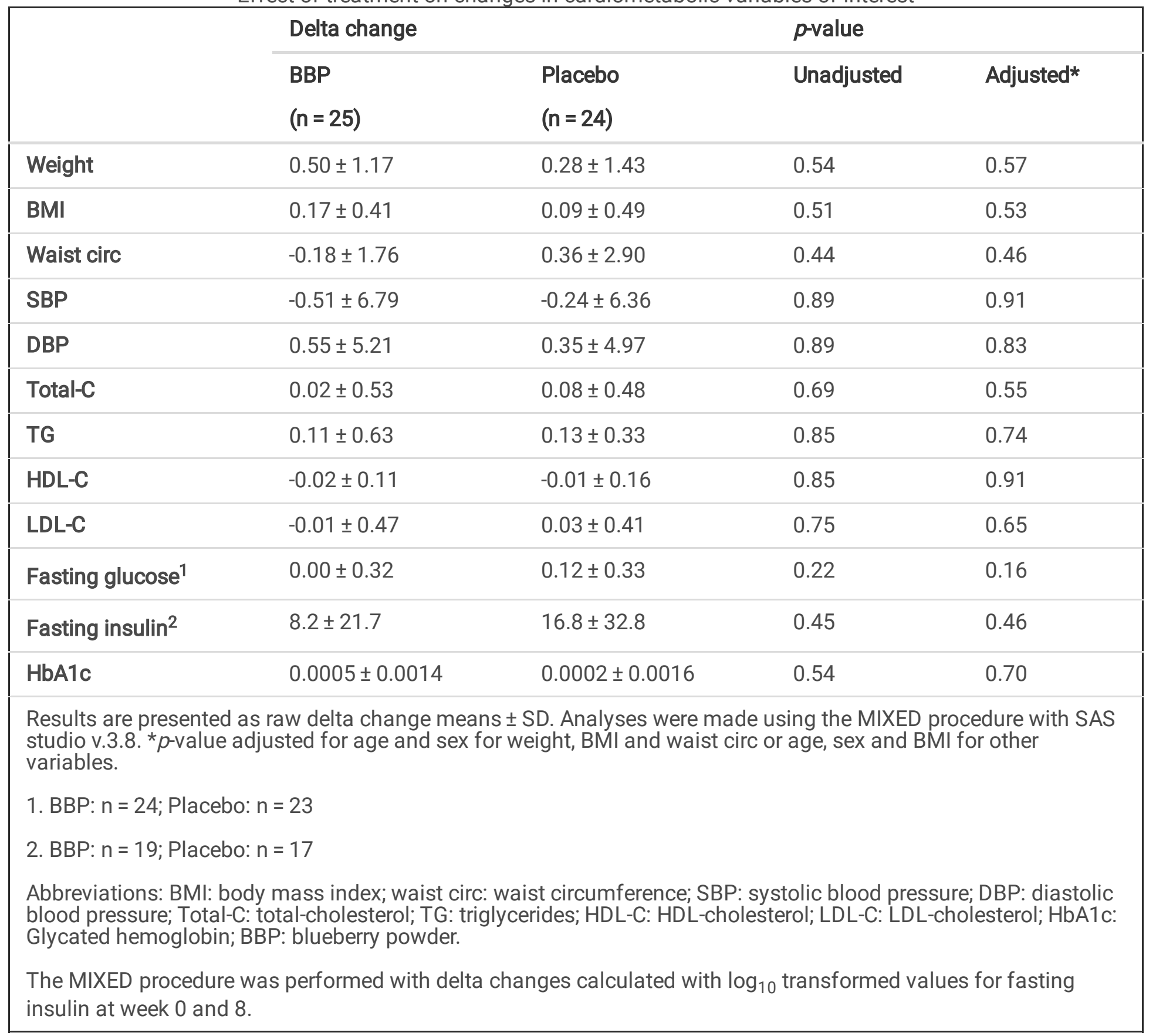

Data from the OGTT-derived markers of insulin resistance are presented in Table 5. For HOMA-IR, a threshold value of 2.5 is used to define individuals with IR (38). For Matsuda index, a value of less than 4.3 predicts IR (38). Only the placebo group had a mean value below this threshold at 8 weeks. Mean HOMA-IR was lower than the defined threshold value for BBP and placebo at week 0 but increased above the threshold after 8 weeks in both groups, though the change was non-significant in the BBP group. Prior to adjusting for potential confounders, there was a significant increase in HOMA-IR, and decrease in Matsuda index in the placebo group only from week 0 to week 8 . Results remained unchanged after adjustment for age, sex and BMI (data not shown). After adjusting for calories, fibre or total sugar intake, individually, time remained significant for Matsuda index $(p<0.04)$, but HOMA-IR was no longer significant $(p>0.05)$. 
Table 5

Effects of treatment and/or time on insulin resistance (HOMA-IR) and insulin sensitivity (Matsuda index)

\begin{tabular}{|c|c|c|c|c|c|c|c|}
\hline & \multicolumn{2}{|l|}{ Week 0} & \multicolumn{2}{|l|}{ Week 8} & \multicolumn{3}{|l|}{ P-value } \\
\hline & BBP & Placebo & BBP & Placebo & Treatment & Time & $\begin{array}{l}\text { Treatment } \\
\text { *Time }\end{array}$ \\
\hline HOMA-IR ${ }^{1}$ & $2.38 \pm 1.19$ & $2.25 \pm 0.93^{a}$ & $2.64 \pm 1.44$ & $2.56 \pm 1.15^{b}$ & 0.80 & 0.02 & 0.53 \\
\hline Matsuda index ${ }^{2}$ & $4.86 \pm 3.17$ & $5.13 \pm 2.80^{a}$ & $4.28 \pm 2.21$ & $3.91 \pm 2.19^{b}$ & 0.71 & 0.006 & 0.08 \\
\hline \multicolumn{8}{|c|}{$\begin{array}{l}\text { Values are mean } \pm \text { SD. Analyses were conducted using the MIXED procedure and LSMEANS with SAS studio v.3.8. } \\
\text { HOMA-IR and Matsuda Index were non-normally distributed and were therefore } \log _{10} \text { transformed. Results that do } \\
\text { not share the same letter (a,b) are significantly different }(\mathrm{p}<0.05 \text { ) from each other. Abbreviations: BBP: blueberry } \\
\text { powder. Significant } p-v a l u e s \text { (unadjusted) are in bold. } 1 \text {. BBP: } n=24 \text { (week } 0), n=23 \text { (week 8); Placebo: } n=23 \\
\text { (week 0), } n=24 \text { (week 8). 2. BBP: } n=18 \text { (week 0), } n=17 \text { (week 8); Placebo: } n=17 \text { (week } 0 \text { and 8). }\end{array}$} \\
\hline
\end{tabular}

\section{TRANSCRIPTOMICS: EFFECT OF BBP ON GENE EXPRESSION}

Results from the transcriptomics analyses are presented in Table 6, Fig. 3 and Fig. 4. The assessment of differential transcript expression revealed a total of 49 genes differentially expressed at FDR-adjusted $p$-value $<0.05$, which were differentially expressed from week 0 to week 8 in the BBP intervention group (Table 6). Statistically significant fold changes in differentially expressed genes ranged from - 1.4 (NT5C3A, NM_001002010) to 1.4 (DDX11L5, NR_051986), with 12 genes showing at least a 1.25-fold change (Fig. 3). Individual changes in gene expression for the top differentially up- and down-regulated genes are shown in Fig. 4. Pathway enrichment analysis revealed that most differentially expressed genes were clustered into immune-related pathways, as shown by the top-five significantly enriched GO-BP categories (Fig. 5-A), including "defense response to virus" ( $n=16$ genes, BH-p = 3.0 $\times 10^{-5}$ ), "response to virus" ( $\left.n=18, \mathrm{BH}-\mathrm{p}=3.7 \times 10^{-5}\right)$, "cellular extravasation" $\left(\mathrm{n}=8, \mathrm{BH}-\mathrm{p}=3.6 \times 10^{-4}\right)$, "response to lipopolysaccharide" $\left(n=15, \mathrm{BH}-\mathrm{p}=3.2 \times 10^{-3}\right)$ and "response to molecule of bacterial origin" $\left(\mathrm{n}=15, \mathrm{BH}-\mathrm{p}=4.1 \times 10^{-3}\right)$. This is consistent with the five significantly enriched pathways found in the Reactome database (Fig. 5-B), including "interferon alpha/beta signaling" ( $n=8$ genes, $\left.\mathrm{BH}-\mathrm{p}=1.4 \times 10^{-3}\right)$, "interferon signaling" $\left(\mathrm{n}=10, \mathrm{BH}-\mathrm{p}=3.3 \times 10^{-2}\right)$, "antimicrobial peptides" ( $\left.n=7, \mathrm{BH}-\mathrm{p}=3.3 \times 10^{-2}\right)$, "alpha defensins" $\left(n=3, \mathrm{BH}-\mathrm{p}=3.3 \times 10^{-2}\right)$ and "caspase-mediated cleavage of cytoskeletal proteins" ( $\left.n=3, \mathrm{BH}-\mathrm{p}=4.8 \times 10^{-2}\right)$. Finally, an immune-related KEGG pathway was also found to be significantly enriched, the "NOD-like receptor signaling pathway" ( $n=10, \mathrm{BH}-\mathrm{p}=9.8 \times 10^{-3}$; network plot not shown). 
Table 6

Transcriptomics results for significant $(p<0.05)$ changes in gene expression from week 0 to week 8 in BBP group

\begin{tabular}{|c|c|c|c|c|}
\hline $\begin{array}{l}\text { Accession } \\
\text { Number }\end{array}$ & FC & $\begin{array}{l}\mathrm{q}- \\
\text { value }\end{array}$ & Gene Symbol & Gene Name \\
\hline NR_051986 & 1.42 & 0.049 & $D D X 11 L 5$ & DEAD/H-box helicase 11 like 5 \\
\hline NR_028326 & 1.40 & 0.030 & LINC01001 & long intergenic non-protein coding RNA 1001 \\
\hline NM_005091 & 1.37 & 0.025 & PGLYRP1 & peptidoglycan recognition protein 1 \\
\hline NM_003245 & 1.34 & 0.014 & TGM3 & transglutaminase 3 \\
\hline NM_138568 & 1.32 & 0.020 & EXOC3L2 & exocyst complex component 3 like 2 \\
\hline NM_001284295 & 1.31 & 0.026 & CHPF2 & chondroitin polymerizing factor 2 \\
\hline NM_001363494 & 1.27 & 0.014 & SLC12A9 & solute carrier family 12 member 9 \\
\hline NM_001168298 & 1.26 & 0.034 & CXCR2 & C-X-C motif chemokine receptor 2 \\
\hline NM_001319196 & 1.24 & 0.042 & S100A8 & S100 calcium binding protein A8 \\
\hline NM_000904 & 1.21 & 0.027 & NQO2 & N-ribosyldihydronicotinamide:quinone reductase 2 \\
\hline NM_000804 & 1.21 & 0.038 & FOLR3 & folate receptor gamma \\
\hline NR_033429 & 1.21 & 0.038 & ABTB1 & ankyrin repeat and BTB domain containing 1 \\
\hline NM_001329425 & 1.21 & 0.049 & $R G L 4$ & ral guanine nucleotide dissociation stimulator like 4 \\
\hline NM_001320458 & 1.21 & 0.049 & WNT9B & Wnt family member 9B \\
\hline NM_001320605 & 1.21 & 0.026 & ICAM3 & intercellular adhesion molecule 3 \\
\hline NM_001286447 & 1.21 & 0.039 & RIPOR2 & RHO family interacting cell polarization regulator 2 \\
\hline NM_001319201 & 1.21 & 0.049 & S100A8 & S100 calcium binding protein A8 \\
\hline NM_205837 & 1.20 & 0.020 & LST1 & leukocyte specific transcript 1 \\
\hline NM_148962 & 1.19 & 0.020 & OXER1 & oxoeicosanoid receptor 1 \\
\hline NM_005451 & 1.19 & 0.042 & PDLIM7 & PDZ and LIM domain 7 \\
\hline NM_013416 & 1.18 & 0.030 & NCF4 & neutrophil cytosolic factor 4 \\
\hline NM_001294333 & 1.17 & 0.020 & ATP6VOB & ATPase $\mathrm{H}+$ transporting V0 subunit b \\
\hline NM_031925 & 1.17 & 0.028 & TMEM120A & transmembrane protein $120 \mathrm{~A}$ \\
\hline NM_000578 & 1.17 & 0.034 & SLC11A1 & solute carrier family 11 member 1 \\
\hline NM_002756 & 1.17 & 0.049 & MAP2K3 & mitogen-activated protein kinase kinase 3 \\
\hline NM_001318325 & 1.16 & 0.047 & NUP214 & nucleoporin 214 \\
\hline NR_028325 & 1.16 & 0.049 & LOC100132062 & uncharacterized LOC100132062 \\
\hline NM_001142573 & 1.16 & 0.049 & IMPDH1 & inosine monophosphate dehydrogenase 1 \\
\hline
\end{tabular}

FC indicates the gene expression fold change from week 0 to week 8. q-value stands for False Discovery Rate (FDR)-adjusted p-values from paired t-tests. 


\begin{tabular}{|c|c|c|c|c|}
\hline $\begin{array}{l}\text { Accession } \\
\text { Number }\end{array}$ & FC & $\begin{array}{l}\mathrm{q}- \\
\text { value }\end{array}$ & Gene Symbol & Gene Name \\
\hline NM_001785 & 1.15 & 0.030 & $C D A$ & cytidine deaminase \\
\hline NM_031968 & 1.15 & 0.038 & NARF & nuclear prelamin A recognition factor \\
\hline NM_002455 & 1.14 & 0.030 & MTX1 & metaxin 1 \\
\hline NM_006755 & 1.14 & 0.049 & TALD01 & transaldolase 1 \\
\hline NM_004037 & 1.13 & 0.049 & AMPD2 & adenosine monophosphate deaminase 2 \\
\hline NM_002746 & 1.12 & 0.049 & MAPK3 & mitogen-activated protein kinase 3 \\
\hline NM_207354 & 1.11 & 0.034 & $A N K R D 13 D$ & ankyrin repeat domain $13 \mathrm{D}$ \\
\hline NR_135579 & 1.11 & 0.049 & ZNF652 & zinc finger protein 652 \\
\hline NM_014597 & -1.10 & 0.041 & DNTTIP2 & $\begin{array}{l}\text { deoxynucleotidyltransferase terminal interacting protein } \\
2\end{array}$ \\
\hline NM_004094 & -1.13 & 0.020 & EIF2S1 & eukaryotic translation initiation factor 2 subunit alpha \\
\hline NM_018471 & -1.13 & 0.030 & ZC3H15 & zinc finger $\mathrm{CCCH}$-type containing 15 \\
\hline NM_001079864 & -1.13 & 0.049 & TAX1BP1 & Tax1 binding protein 1 \\
\hline NM_018164 & -1.15 & 0.030 & INTS13 & integrator complex subunit 13 \\
\hline NM_018229 & -1.15 & 0.041 & AP5M1 & adaptor related protein complex 5 subunit mu 1 \\
\hline NM_003142 & -1.16 & 0.030 & $S S B$ & small RNA binding exonuclease protection factor La \\
\hline NM_032383 & -1.16 & 0.049 & HPS3 & $\begin{array}{l}\text { HPS3 biogenesis of lysosomal organelles complex } 2 \\
\text { subunit } 1\end{array}$ \\
\hline NM_174916 & -1.21 & 0.049 & UBR1 & ubiquitin protein ligase E3 component n-recognin 1 \\
\hline NM_005983 & -1.26 & 0.020 & SKP2 & S-phase kinase associated protein 2 \\
\hline NM_006294 & -1.27 & 0.020 & UQCRB & ubiquinol-cytochrome c reductase binding protein \\
\hline NM_024546 & -1.27 & 0.028 & $O B / 1$ & ORC ubiquitin ligase 1 \\
\hline NM_001002010 & -1.44 & 0.041 & NT5C3A & 5'-nucleotidase, cytosolic IIIA \\
\hline
\end{tabular}

\section{METABOLOMICS: EFFECT OF BBP ON METABOLITES}

The paired t-test analysis demonstrated that following BBP supplementation, a total of 50 metabolites had significantly different blood levels (paired t-test p-value $<0.05$ ), as compared to pre-supplementation levels. This number was reduced to 35 metabolites after applying the statistical significance criteria $(>1.25$-fold change and $>50 \%$ of significant metabolite counts) (Fig. 6 and Table 7). Metabolites showing a significant reduction of their blood levels following the BBP supplementation are shown on the top-left corner of the volcano plot, and those showing a significant increase are shown on the top-right corner of the paired volcano plot (Fig. 6). The top-five under- and overabundant metabolites are shown in paired box-plots in Fig. 7. Among the under-abundant metabolites, those showing a more significant decrease are ornithine (Orn), hypoxanthine, diacylglycerol DAG(16:1/18:2), ceramide 
Cer(d16:1/24:0) and indoxyl sulfate (Ind-SO4). On the other hand, triglycerides (TG(16:0/30:2), TG(20:2/34:2), $\mathrm{TG}(16: 1 / 32: 0), \mathrm{TG}(14: 0 / 34: 3), \mathrm{TG}(16: 1 / 32: 0)$ are among the metabolites that have undergone a significant increase following the BBP supplementation. 
Table 7

Metabolomics results for significant $(p<0.05)$ changes in metabolites from week 0 to week 8 in BBP group

\begin{tabular}{|c|c|c|c|}
\hline $\begin{array}{l}\text { Abbreviated } \\
\text { Metabolite Name }\end{array}$ & Super Pathway & p-value & HMDB \\
\hline 1-Met-His & Aminoacids Related & 0.019 & HMDB0000001 \\
\hline 3-Met-His & Aminoacids Related & 0.026 & HMDB0000479 \\
\hline C3 & Acylcarnitines & 0.020 & HMDB0000824 \\
\hline Cer(d16:1/22:0) & Ceramides & 0.024 & \\
\hline Cer(d16:1/24:0) & Ceramides & 0.012 & \\
\hline Cer(d18:0/22:0) & Dihydroceramides & 0.048 & HMDB0011765 \\
\hline Cer(d18:1/18:0) & Ceramides & 0.048 & HMDB0004950 \\
\hline Cer(d18:2/24:0) & Ceramides & 0.036 & \\
\hline DG(16:1/18:2) & Diacylglycerols & 0.010 & HMDB0007132 \\
\hline DG(18:2/20:4) & Diacylglycerols & 0.032 & HMDB0007257 \\
\hline HArg & Aminoacids Related & 0.039 & HMDB0000670 \\
\hline HexCer(d18:1/16:0) & Glycosylceramides & 0.022 & \\
\hline HipAcid & Carboxylic Acids & 0.016 & HMDB0000714 \\
\hline Hypoxanthine & Nucleobases Related & 0.007 & HMDB0000157 \\
\hline Ind-SO4 & Indoles Derivatives & 0.016 & HMDB0000682 \\
\hline Kynurenine & Aminoacids Related & 0.028 & HMDB0000684 \\
\hline Orn & Aminoacids Related & 0.002 & HMDB0000214 \\
\hline p-Cresol-SO4 & Cresols & 0.029 & HMDB0011635 \\
\hline PC aa C32:3 & Glycerophospholipids & 0.031 & HMDB0007876 \\
\hline PC aa C38:1 & Glycerophospholipids & 0.036 & HMDB0007894 \\
\hline PC aa $\mathrm{C} 40: 3$ & Glycerophospholipids & 0.018 & \\
\hline PC aa $\mathrm{C} 42: 2$ & Glycerophospholipids & 0.039 & \\
\hline PC aa C42:4 & Glycerophospholipids & 0.045 & HMDB0008191 \\
\hline PC ae C32:2 & Glycerophospholipids & 0.031 & HMDB0013411 \\
\hline PC ae C36:0 & Glycerophospholipids & 0.049 & HMDB0013406 \\
\hline SM C20:2 & Sphingolipids & 0.032 & \\
\hline SM C26:1 & Sphingolipids & 0.043 & HMDB0013461 \\
\hline TG(14:0/34:1) & Triacylglycerols & 0.042 & \\
\hline
\end{tabular}




\begin{tabular}{|c|c|c|c|}
\hline $\begin{array}{l}\text { Abbreviated } \\
\text { Metabolite Name }\end{array}$ & Super Pathway & p-value & HMDB \\
\hline TG(14:0/34:3) & Triacylglycerols & 0.015 & \\
\hline TG(16:0/30:2) & Triacylglycerols & 0.006 & \\
\hline $\mathrm{TG}(16: 0 / 32: 1)$ & Triacylglycerols & 0.040 & HMDB0044726 \\
\hline TG(16:1/32:0) & Triacylglycerols & 0.014 & HMDB05359 \\
\hline TG(18:0/36:5) & Triacylglycerols & 0.021 & HMDB05426 \\
\hline $\mathrm{TG}(20: 2 / 34: 2)$ & Triacylglycerols & 0.012 & \\
\hline TG(20:4/32:0) & Triacylglycerols & 0.029 & HMDB05363 \\
\hline
\end{tabular}

The score plot derived from smPLS-DA shows the complete separation of pre- and post-supplementation groups, without overlap (Fig. 8). Component 1 was primarily responsible for group discrimination, accounting for a $13 \%$ of the variance, with component 2 accounting for $2.7 \%$. The ten metabolites associated with the first component and underlying the discrimination between pre-and post-supplementation groups are shown in the loadings panel of the first component (Fig. 8). Most of these metabolites, whose relative contribution to group discrimination, or loading weight, is highlighted in Fig. 8, have been previously identified as differentially abundant between pre- and postsupplementation (Fig. 7). The top five metabolites exhibiting significant reductions include: ornithine, hypoxanthine, DG161_182, Cerd161/240 and Ind_SO4. The top five metabolites exhibiting significant increases in response to BBP supplementation include: TG160_302, TG202_342, TG161_320 and TG140_343.

\section{Discussion}

This randomized placebo-controlled clinical trial investigated the effects of an 8-week BBP intervention on metabolic markers of cardiometabolic health, transcriptomics and metabolomics in adults at risk of developing MetS. Compared to placebo, BBP intake had no major, significant effect on cardiometabolic health or glycemic response after 8 weeks. However, transcriptomics and metabolomics data indicate significant changes occurring in response to BBP, thus demonstrating that BBP may have potential health-related effects, perhaps after an intervention longer than 8 weeks and/or with whole blueberry consumption or a higher dosage.

Results from studies assessing the impact of highbush blueberries on health have been variable. With a 28-day supplementation of $11 \mathrm{~g} \mathrm{BBP}$ daily, flow-mediated dilation improved and SBP was significantly reduced in men (39). Similarly, a reduction in SBP and DBP was observed in a study of comparable size and identical duration and dose as in the present study, but composed mainly of women with the MetS (11). However with half of the BBP dose used by Basu et al. (11) and in the present study, no improvement in SBP or DBP following a 6-week BBP supplementation were observed in a sample of men (19). Through a meta-analysis of studies with similar designs to the present RCT (40), the overall body of evidence suggests that highbush BBP does not have a significant effect on SBP $(-0.28 \mathrm{mmHg}$ [95\% Cl: $-1.11,0.56])$ and DBP $(-0.50 \mathrm{mmHg}[95 \% \mathrm{Cl}:-1.24,0.24])(40)$. It is however possible that whole blueberries 
have a significant effect on BP, as a meta-analysis of RCTs reported a favourable effect of 2 to 24-week duration of supplementation with whole berries (including studies on cranberries, bilberries, blueberries, whortleberries, elderberries or raspberries), on SBP (-2.72 mmHg [95\% Cl: -5.32, -0.12]) (41).

In contrast to findings made in human interventions, numerous animal studies reported benefits of blueberries alone or mixed with other berries on weight management (42-44), markers of glucose/insulin resistance or sensitivity $(10,42-$ $46)$, lipid profile $(42,47,48)$, vascular health $(49,50)$, kidney function $(51)$ or inflammatory markers $(10,42-44,50-53)$. Results from studies assessing other MetS phenotype parameters have been consistent with our findings overall. Using a similar design and intervention protocol, Basu and colleagues reported no difference between the placebo and the blueberry group for serum glucose concentration, lipid profile, HbA1c and HOMA-IR (11). Similarly, in a study providing blueberry smoothies for a 6-week period, no impact on lipid, fasting glucose and insulin levels or insulin sensitivity were observed (18). In these two clinical trials, obese participants with MetS were recruited and similar dose of BBP were given as in the present study. Moreover, a meta-analysis reported no effect of berry supplementation on total-C, HDL-C and TG levels, but the berry supplementation did lead to a significant reduction in LDL-C (-0.21 mmol/L [95\% Cl: $-0.34,-0.07])$, fasting glucose (-0.10 mmol/L [95\% Cl: $-0.17,-0.03]), \mathrm{HbA} 1 \mathrm{c}[-0.20 \%$ [95\% Cl: $-0.39,-0.01])$ and BMI $\left(-0.36 \mathrm{~kg} / \mathrm{m}^{2}\right.$ [95\% Cl: $\left.\left.-0.54,-0.18\right]\right)(41)$. Results reported herein are comparable to those reported in previous studies and in a meta-analysis including healthy and metabolically deteriorated individuals (40). It is also important to keep in mind that although at least one cardiometabolic parameter was improved in most human intervention studies with BBP (e.g. blood pressure or inflammation biomarkers), the effect size remained quite small.

Fasting insulin and glucose levels are limited measures of insulin sensitivity. The gold standard for its assessment is the euglycemic clamp but because it is a strenuous procedure, 120- or 180-minute OGTTs are more often used to get information on body glucose disposal efficiency after a test meal or a glucose load (54) from which various indices have been derived to get a better idea of glucose and insulin dynamics $(38,54)$. One of them, HOMA-IR, is very common and the simplest to compute (28). Another, the Matsuda index, is a good approximation of whole-body insulin sensitivity $(29,54)$. Many studies have reported on these outcomes in response to blueberry interventions. Similar to the results presented herein, a 12-week tart cherry juice supplementation had no effect on HOMA-IR or insulin concentration (55). Furthermore, a meta-analysis of pomegranate supplementation reported no change on mean HOMA-IR with a pooled estimated effect of -0.04 [95\% Cl: -0.53, 0.46] (56). Moreover, a red wine polyphenol supplementation study for 8 weeks did not improve HOMA-IR, fasting glucose and insulin concentrations nor Matsuda index following a mixed-meal test in obese participants (57).

A possible explanation for the absence of effect of the BBP on cardiometabolic risk factors in the present study may be attributable to the extra calories provided by the powders, being added to the usual diet of study participants. While the analysis of energy intake did not reveal significant changes between baseline and treatment weeks, participants of both groups consumed significantly more carbohydrates at weeks 4 and 8 in comparison to week 0 , of whom about two third were sugars. Higher carbohydrate intake has been associated with lower HDL-C and higher TG concentrations (58). The net increase in the intake of carbohydrates from the powders might have masked the potential lowering effects of BBP antioxidants on cardiometabolic parameters if the participants did not compensate by reducing their consumption of carbohydrates from other foods and beverages.

The transcriptomics and metabolomics analyses allowed for the identification and understanding of activated metabolic pathways following the BBP dietary intervention. BBP had a significant impact on 35 individual metabolites and the expression of 49 genes, thus providing other important insights for future research exploring health-related outcomes resulting from BBP supplementation. It is possible that BBP had an effect on markers of inflammation, immunity and oxidative stress, but these outcomes were not investigated in the present study. Further exploration of 
the roles of each of these metabolites and genes can help guide future research endeavours. For example, ornithine, produced via the urea cycle, is a non-essential amino acid (59). The substrate action of ornithine can lead to excessive polyamine synthesis which plays a role in modulating the development of certain types of cancer $(59,60)$. This protective role has been supported by previous, in vitro, pre-clinical and clinical research on the effects of blueberries and other berries (61). Indeed, future research is needed to explore this further and investigate the metabolic relevance of a reduction in plasma ornithine concentrations following blueberry supplementation. There was also a significant reduction in hypoxanthine following BBP supplementation. Circulating concentrations of hypoxanthine, a purine molecule which is a by-product of adenosine triphosphate catabolism; are elevated following an ischemic event (62). On the other hand, the increase in plasma hippuric acid we observed has been previously reported following anthocyanin supplementation (20,63-65). The significant increases in several TG metabolites following BBP supplementation was, to our knowledge, a novel finding. However, this finding was perhaps not surprising given the well-established relationship between carbohydrate intake and plasma TG (66). Therefore, this finding of increased TG metabolites further relates to our dietary results demonstrating a significant increase in carbohydrates and total sugars throughout the intervention (due to the nutritional breakdown of the intervention products: Supplementary Table 1).

Pathway analyses can determine if differentially expressed genes are part of predefined physiological networks more than what would be expected by chance alone. This allows for the generation of mechanistic hypotheses and identification of putative mechanisms (67). It was interesting to find that differentially regulated genes were clustered into immune-related pathways, thus suggesting that the BBP supplementation could have anti-inflammatory effects. This finding is consistent with a formerly conducted transcriptomic analysis following a 4-week 1L/day blueberryapple juice dietary intervention, whereby the researchers also found gene expression changes in immune response pathways alongside signalling pathways for apoptosis, cell adhesion and lipid metabolism (68). This further relates to previous research indicating that blueberries can have immunomodulatory effects and reduce oxidative stress in adults with MetS (69), and that a blueberry green tea polyphenol soy complex could have a potential protective role against viral infections in athletes (70). Moreover, a randomized controlled trial of $38 \mathrm{~g} /$ day BBP for 6 weeks resulted in a significant increase in natural killer cells, a type of peripheral lymphocyte playing a key role in the immune response (71). The identified changes in key molecular signalling pathways and metabolic regulatory networks can ultimately be used to identify relevant biological and metabolic pathways that can become targets for therapy and may assist researchers in developing new hypotheses related to the health benefits of blueberries.

Taken together, while BBP did not appear to impact specific cardiometabolic risk factors related to MetS within the given time frame of the study, the significant changes in gene expression and metabolites indicate the potential for BBP to impact various health outcomes, particularly those related to immunity. MetS-related health outcomes may occur beyond an 8-week intake period or from an intervention with whole blueberries rather than BBP or a higher dosage. For example, a long-term BBP supplementation study in individuals with MetS investigated the benefits of taking $13 \mathrm{~g}$ or $22 \mathrm{~g} \mathrm{BBP}$ on a daily basis (representing respectively a quarter and a half of the dose given in the present study), for a period of 6 months found significant improvements of endothelial function and arterial stiffness in subjects consuming the highest dose of BBP (20).

This study has some limitations. First, it included premenopausal women, but menstrual cycle hormonal fluctuation can influence cardiometabolic biomarkers especially those associated to the lipid profile (72) and endothelial function (73). Since the only constraint regarding powder intake was not to heat it, it is possible that consuming it with food such as milk could have had an effect on its antioxidant properties due to the matrix effect (74). Furthermore, milled freeze-dried highbush BBP was used as a surrogate of whole fresh blueberries for practical reasons. Although this method has been reported to preserve blueberry antioxidants $(75,76)$, we cannot discard the possibility that fresh 
blueberries may exert more potent cardiometabolic benefits than freeze-dried and milled into powder. Nonetheless, the strengths of the present study include its randomized, placebo-controlled, double-blind design that limits the influence of confounding factors, which may bias estimates of treatment effects. Compliance to treatment was high and study directives were well followed by participants. Powders were of similar aspect and taste and, unless comparing BBP and placebo powder side to side, participants were probably unable to discover to which treatment they were randomized. Also, it is important to highlight that blueberry supplementation studies in healthy but overweight individuals at risk of developing MetS are less frequent thus highlighting the novelty of this work. Most studies have been conducted on subjects older than those in the present study and/or having a MetS diagnosis. Moreover, in addition to reporting changes for traditional biomarkers of cardiometabolic health, this trial also includes analyses on glucose and insulin resistance/sensitivity indices, which are better indicators than fasting values alone. The literature was especially lacking human intervention reporting these measurements. Lastly, to our knowledge, this was the first study to assess changes in gene expression resulting from BBP supplementation. Finally, this study is primarily generalizable to men and women at risk of MetS.

\section{Conclusion}

In conclusion, no significant effects on plasma cardiometabolic risk factors were observed herein following an 8-week supplementation with BBP. However, given the significant changes in gene expression and several metabolites following BBP supplementation, it is plausible that a longer follow-up and/or higher dosage could have resulted in significant improvements in plasma MetS parameters. Future BBP interventional clinical trials should seek to explore health outcomes related to the changes in gene expression and metabolites reported in the current trial, while providing an intervention $>8$ weeks, intervening with whole blueberries, and/or providing a higher dosage of BBP.

\section{Abbreviations}

BBP

blueberry powder

BMI

body mass index

DBP

diastolic blood pressure

FFQ

food frequency questionnaire

IR

insulin resistance

MetS

metabolic syndrome

ROS

reactive oxygen species

SBP

systolic blood pressure

TG

triglycerides

\section{Declarations}




\section{Ethics Approval and Consent to Participate}

This study was approved by the Ethics Committee of Université Laval (2017-135 R-3) and registered at https://clinicaltrials.gov/ (NCT03266055). All subjects signed a written informed consent prior their participation to the study.

\section{Consent for Publications}

Not applicable

\section{Availability of Data and Material}

Please contact authors for data requests.

\section{Competing Interests}

The authors declare that they have no competing interests.

\section{Funding}

This work was supported by the U.S. Highbush Blueberry Council (USHBC). The funders were not involved in the study design, data analysis, or interpretation of results. Marie-Claude Vohl is a Canada Research Chair in Genomics Applied to Nutrition and Metabolic Health. André Marette is holding a Pfizer research Chair in the pathogenesis of insulin resistance and cardiovascular diseases. Michèle Rousseau received a studentship from the INITIA Foundation. Justine Horne was supported through postdoctoral fellowships from the Canadian Institutes of Health Research, Centre Nutrition, Santé et Société (NUTRISS) and the Institut sur la nutrition et les aliments fonctionnels (INAF).

\section{Authors' Contributions}

Conceptualization and design of the experiments: VGa, CC, PC, DR, AM, MCV; clinical supervision: PC, VGa, VGu and MK; data analysis: MR, FG, JTM; formal analysis and writing: MR, JH, JTM; supervision: MCV. Review and editing: all authors. MR, JH, JTM, FG, CC, GP, PC, VGa, VGu, MK, DR, AM and MCV critically revised the manuscript. All authors read and approved the final manuscript.

\section{Acknowledgements}

The authors gratefully acknowledge participants' contribution to our study. We also recognize the work of the clinical investigation unit staff and of Maximilien Franck for their involvement in the study coordination, recruitment of the subjects and data collection.

\section{References}

1. Aguilar M, Bhuket T, Torres S, Liu B, Wong RJ. Prevalence of the metabolic syndrome in the United States, 20032012. JAMA. 2015;313:1973-4.

2. Riediger ND, Clara I. Prevalence of metabolic syndrome in the Canadian adult population. Can Med Assoc J. 2011;183:E1127-34.

3. O’Neill S, O'Driscoll L. Metabolic syndrome: a closer look at the growing epidemic and its associated pathologies: Metabolic syndrome. Obes Rev. 2015;16:1-12. 
4. Rani V, Deep G, Singh RK, Palle K, Yadav UCS. Oxidative stress and metabolic disorders: Pathogenesis and therapeutic strategies. Life Sci. 2016;148:183-93.

5. Kehrer JP, Klotz L-O. Free radicals and related reactive species as mediators of tissue injury and disease: implications for Health. Crit Rev Toxicol. 2015;45:765-98.

6. Kasote DM, Katyare SS, Hegde MV, Bae H. Significance of antioxidant potential of plants and its relevance to therapeutic applications. International Journal of Biological Sciences. 2015;11:982-91.

7. Wu X, Beecher GR, Holden JM, Haytowitz DB, Gebhardt SE, Prior RL. Concentrations of anthocyanins in common foods in the United States and estimation of normal consumption. J Agric Food Chem. 2006;54:4069-75.

8. Martineau LC, Couture A, Spoor D, Benhaddou-Andaloussi A, Harris C, Meddah B, Leduc C, Burt A, Vuong T, Mai Le $P$, et al. Anti-diabetic properties of the Canadian lowbush blueberry Vaccinium angustifolium Ait. Phytomedicine. 2006;13:612-23.

9. Wolfe KL, Kang X, He X, Dong M, Zhang Q, Liu RH. Cellular antioxidant activity of common fruits. J Agric Food Chem. 2008;56:8418-26.

10. DeFuria J, Bennett G, Strissel KJ, Perfield JW, Milbury II, Greenberg PE, Obin AS. MS. Dietary blueberry attenuates whole-body insulin resistance in high fat-fed mice by reducing adipocyte death and its inflammatory sequelae. The Journal of Nutrition. 2009;139:1510.

11. Basu A, Du M, Leyva MJ, Sanchez K, Betts NM, Wu M, Aston CE, Lyons TJ. Blueberries decrease cardiovascular risk factors in obese men and women with metabolic syndrome. The Journal of Nutrition. 2010;140:1582-7.

12. Johnson SA, Figueroa A, Navaei N, Wong A, Kalfon R, Ormsbee LT, Feresin RG, Elam ML, Hooshmand S, Payton $\mathrm{ME}$, et al. Daily blueberry consumption improves blood pressure and arterial stiffness in postmenopausal women with pre- and stage 1-hypertension: A randomized, double-blind, placebo-controlled clinical trial. Journal of the Academy of Nutrition Dietetics. 2015;115:369-77.

13. Bowtell JL, Aboo-Bakkar Z, Conway ME, Adlam A-LR, Fulford J. Enhanced task-related brain activation and resting perfusion in healthy older adults after chronic blueberry supplementation. Appl Physiol Nutr Metab. 2017;42:7739.

14. Miller MG, Hamilton DA, Joseph JA, Shukitt-Hale B. Dietary blueberry improves cognition among older adults in a randomized, double-blind, placebo-controlled trial. Eur J Nutr. 2018;57:1169-80.

15. Cassidy A, Mukamal KJ, Liu L, Franz M, Eliassen AH, Rimm EB. High anthocyanin intake is associated with a reduced risk of myocardial infarction in young and middle-aged women. Circulation. 2013;127:188-96.

16. Muraki I, Imamura F, Manson JE, Hu FB, Willett WC, van Dam RM, Sun Q. Fruit consumption and risk of type 2 diabetes: results from three prospective longitudinal cohort studies. BMJ. 2013;347:f5001-1.

17. Stull AJ, Cash KC, Johnson WD, Champagne CM, Cefalu WT. Bioactives in blueberries improve insulin sensitivity in obese, insulin-resistant men and eomen. The Journal of Nutrition. 2010;140:1764.

18. Stull AJ, Cash KC, Champagne CM, Gupta AK, Boston R, Beyl RA, Johnson WD, Cefalu WT. Blueberries improve endothelial function, but not blood pressure, in adults with metabolic syndrome: A randomized, double-blind, placebo-controlled clinical trial. Nutrients. 2015;7:4107.

19. Riso P, Klimis-Zacas D, Del Bo' C, Martini D, Campolo J, Vendrame S, Møller P, Loft S, De Maria R, Porrini M. Effect of a wild blueberry (Vaccinium angustifolium) drink intervention on markers of oxidative stress, inflammation and endothelial function in humans with cardiovascular risk factors. Eur J Nutr. 2013;52:949-61.

20. Curtis PJ, van der Velpen V, Berends L, Jennings A, Feelisch M, Umpleby AM, Evans M, Fernandez BO, Meiss MS, Minnion $\mathrm{M}$, et al. Blueberries improve biomarkers of cardiometabolic function in participants with metabolic 
syndrome-results from a 6-month, double-blind, randomized controlled trial. The American Journal of Clinical Nutrition. 2019;109:1535-45.

21. Cutler BR, Petersen C, Anandh Babu PV. Mechanistic insights into the vascular effects of blueberries: Evidence from recent studies. Mol Nutr Food Res. 2016;61:1600271.

22. Peña-Romero AC, Navas-Carrillo D, Marín F, Orenes-Piñero E. The future of nutrition: Nutrigenomics and nutrigenetics in obesity and cardiovascular diseases. Critical Reviews in Food Science and Nutrition. Taylor \& Francis; 2018;58:3030-41.

23. Scarsella C, Alméras N, Mauriège P, Blanchet C, Sauvé L, Dewailly E, Bergeron J, Després J-P. Prevalence of metabolic alterations predictive of cardiovascular disease risk in the Québec population. The Canadian Journal of Cardiology. 2003;19:51-7.

24. Labonté M-Ė, Cyr A, Baril-Gravel L, Royer M-M, Lamarche B. Validity and reproducibility of a web-based, selfadministered food frequency questionnaire. Eur J Clin Nutr. 2012;66:166-73.

25. Willett W. Nutritional epidemiology. Third Edition. New York: Oxford University Press; 2013.

26. Loham T, Roche A, Martorel R. Standardization of anthropometric measurements. The Airlie (VA) Consensus Conference. 1988. p. 39-80.

27. Friedewald WT, Levy RI, Fredrickson DS. Estimation of the concentration of low-density lipoprotein cholesterol in plasma, without use of the preparative ultracentrifuge. Clinical chemistry. 1972;18:499-502.

28. Matthews DR, Hosker JP, Rudenski AS, Naylor BA, Treacher DF, Turner RC. Homeostasis model assessment: insulin resistance and beta-cell function from fasting plasma glucose and insulin concentrations in man. Diabetologia. 1985;28:412-9.

29. Matsuda M, DeFronzo RA. Insulin sensitivity indices obtained from oral glucose tolerance testing: comparison with the euglycemic insulin clamp. Diabetes Care. 1999;22:1462-70.

30. Bray NL, Pimentel H, Melsted P, Pachter L. Near-optimal probabilistic RNA-seq quantification. Nat Biotechnol. 2016;34:525-7.

31. McCarthy DJ, Chen Y, Smyth GK. Differential expression analysis of multifactor RNA-Seq experiments with respect to biological variation. Nucleic Acids Res. 2012;40:4288-97.

32. Yu G, Wang LG, Han Y, He QY. ClusterProfiler: An R package for comparing biological themes among gene clusters. OMICS A Journal of Integrative Biology. Mary Ann Liebert, Inc.; 2012;16:284-7.

33. Chong J, Xia J. MetaboAnalystR: an R package for flexible and reproducible analysis of metabolomics data. Bioinformatics. 2018;34:4313-4.

34. Cao MD, Giskeødegård GF, Bathen TF, Sitter B, Bofin A, Lønning PE, Lundgren S, Gribbestad IS. Prognostic value of metabolic response in breast cancer patients receiving neoadjuvant chemotherapy. 2012.

35. Westerhuis JA, van Velzen EJJ, Hoefsloot HCJ, Smilde AK. Multivariate paired data analysis: Multilevel PLSDA versus OPLSDA. Metabolomics. 2010;6:119-28.

36. Lê Cao KA, Boitard S, Besse P. Sparse PLS discriminant analysis: Biologically relevant feature selection and graphical displays for multiclass problems. BMC Bioinformatics BioMed Central. 2011;12:253.

37. Rohart F, Gautier B, Singh A, Lê Cao KA. mixOmics: An R package for 'omics feature selection and multiple data integration. Schneidman D, editor. PLoS Computational Biology. Public Library of Science; 2017;13:e1005752.

38. Gutch M, Kumar S, Razi S, Gupta K, Gupta A. Assessment of insulin sensitivity/resistance. Indian J Endocrinol Metabol. 2015;19:160.

39. Rodriguez-Mateos A, Istas G, Boschek L, Feliciano RP, Mills CE, Boby C, Gomez-Alonso S, Milenkovic D, Heiss C. Circulating anthocyanin metabolites mediate vascular benefits of blueberries: Insights from randomized 
controlled trials, Metabolomics, and Nutrigenomics. The Journals of Gerontology: Series A. 2019;74:967-76.

40. Zhu Y, Sun J, Lu W, Wang X, Wang X, Han Z, Qiu C. Effects of blueberry supplementation on blood pressure: a systematic review and meta-analysis of randomized clinical trials. J Hum Hypertens. 2017;31:165-71.

41. Huang H, Chen G, Liao D, Zhu Y, Xue X. Effects of berries consumption on cardiovascular risk factors: A metaanalysis with trial sequential analysis of randomized controlled Trials. Scientific Reports. 2016;6.

42. Lee I-C, Kim DY, Choi BY. Antioxidative activity of blueberry leaf extract prevents high-fat diet-induced obesity in C57BL/6 Mice. Journal of Cancer Prevention. 2014;19:209-15.

43. Aranaz P, Romo-Hualde A, Zabala M, Navarro-Herrera D, Ruiz de Galarreta M, Gil AG, Martinez JA, Milagro FI, González-Navarro CJ. Freeze-dried strawberry and blueberry attenuates diet-induced obesity and insulin resistance in rats by inhibiting adipogenesis and lipogenesis. Food Funct. 2017;8:3999-4013.

44. Wu T, Gao Y, Guo X, Zhang M, Gong L. Blackberry and blueberry anthocyanin supplementation counteract high-fatdiet-induced obesity by alleviating oxidative stress and inflammation and accelerating energy expenditure. Oxidative Medicine Cellular Longevity. 2018;2018:1-9.

45. Elks CM, Terrebonne JD, Ingram DK, Stephens JM. Blueberries improve glucose tolerance without altering body composition in obese postmenopausal mice: Blueberries and Postmenopausal Obesity. Obesity. 2015;23:573-80.

46. Liu W, Mao Y, Schoenborn J, Wang Z, Tang G, Tang X. Whole blueberry protects pancreatic beta-cells in dietinduced obese mouse. Nutrition \& Metabolism. 2019;16.

47. Vendrame S, Daugherty A, Kristo AS, Klimis-Zacas D. Wild blueberry (Vaccinium angustifolium)-enriched diet improves dyslipidaemia and modulates the expression of genes related to lipid metabolism in obese Zucker rats. Br J Nutr. 2014;111:194-200.

48. Jiao X, Wang Y, Lin Y, Lang Y, Li E, Zhang X, Zhang Q, Feng Y, Meng X, Li B. Blueberry polyphenols extract as a potential prebiotic with anti-obesity effects on C57BL/ $6 \mathrm{~J}$ mice by modulating the gut microbiota. The Journal of Nutritional Biochemistry. 2019;64:88-100.

49. Kalea AZ, Clark K, Schuschke DA, Kristo AS, Klimis-Zacas DJ. Dietary enrichment with wild blueberries (Vaccinium angustifolium) affects the vascular reactivity in the aorta of young spontaneously hypertensive rats. The Journal of Nutritional Biochemistry. 2010;21:14-22.

50. Mykkänen OT, Huotari A, Herzig K-H, Dunlop TW, Mykkänen H, Kirjavainen PV. Wild blueberries (Vaccinium myrtillus) alleviate inflammation and hypertension associated with developing obesity in mice fed with a high-fat diet. PLoS ONE. 2014;9:e114790.

51. Nair AR, Elks CM, Vila J, Del Piero F, Paulsen DB, Francis J. A blueberry-enriched diet improves renal function and reduces oxidative stress in metabolic syndrome animals: Potential mechanism of TLR4-MAPK signaling pathway. PLoS ONE. 2014;9:e111976.

52. Vendrame S, Daugherty A, Kristo AS, Riso P, Klimis-Zacas D. Wild blueberry (Vaccinium angustifolium) consumption improves inflammatory status in the obese Zucker rat model of the metabolic syndrome. The Journal of Nutritional Biochemistry. 2013;24:1508-12.

53. Vendrame S, Tsakiroglou P, Kristo AS, Schuschke DA, Klimis-Zacas D. Wild blueberry consumption attenuates local inflammation in the perivascular adipose tissue of obese Zucker rats. Appl Physiol Nutr Metab. 2016;41:1045-51.

54. Muniyappa R, Lee S, Chen H, Quon MJ. Current approaches for assessing insulin sensitivity and resistance in vivo: advantages, limitations, and appropriate usage. American Journal of Physiology-Endocrinology Metabolism. 2008;294:E15-26. 
55. Chai SC, Davis K, Wright RS, Kuczmarski MF, Zhang Z. Impact of tart cherry juice on systolic blood pressure and low-density lipoprotein cholesterol in older adults: a randomized controlled trial. Food Funct. 2018;9:3185-94.

56. Huang $H$, Liao D, Chen G, Chen H, Zhu Y. Lack of efficacy of pomegranate supplementation for glucose management, insulin levels and sensitivity: evidence from a systematic review and meta-analysis. Nutrition Journal. 2017;16.

57. Woerdeman J, Del Rio D, Calani L, Eringa EC, Smulders YM, Serné EH. Red wine polyphenols do not improve obesity-associated insulin resistance: A randomized controlled trial. Diabetes Obesity Metabolism. 2018;20:20610.

58. Ma Y, Li Y, Chiriboga DE, Olendzki BC, Hebert JR, Li W, Leung K, Hafner AR, Ockene IS. Association between carbohydrate intake and serum lipids. J Am Coll Nutr. 2006;25:155-63.

59. Sivashanmugam M, U JJ,V. K.N. S. Ornithine and its role in metabolic diseases: An appraisal. Biomed Pharmacother. 2017;86:185-94.

60. Heller JS, Chen KY, Kyriakidis DA, Fong WF, Canellakis ES. The modulation of the induction of ornithine decarboxylase by spermine, spermidine and diamines. J Cell Physiol. 1978;96:225-34.

61. Neto CC. Cranberry and blueberry: Evidence for protective effects against cancer and vascular diseases. Mol Nutr Food Res. 2007;51:652-64.

62. Farthing DE, Farthing CA, Xi L. Inosine and hypoxanthine as novel biomarkers for cardiac ischemia: From bench to point-of-care. Exp Biol Med (Maywood). 2015;240:821-31.

63. Rodriguez-Mateos A, Del Pino-García R, George TW, Vidal-Diez A, Heiss C, Spencer JPE. Impact of processing on the bioavailability and vascular effects of blueberry (poly)phenols. Mol Nutr Food Res. 2014;58:1952-61.

64. Ferrars RM de, Cassidy A, Curtis P, Kay CD. Phenolic metabolites of anthocyanins following a dietary intervention study in post-menopausal women. Mol Nutr Food Res. 2014;58:490-502.

65. Nieman DC, Kay CD, Rathore AS, Grace MH, Strauch RC, Stephan EH, Sakaguchi CA, Lila MA. Increased plasma levels of gut-derived phenolics linked to walking and running following two weeks of flavonoid supplementation. Nutrients. Multidisciplinary Digital Publishing Institute; 2018;10:1718.

66. Parks EJ, Hellerstein MK. Carbohydrate-induced hypertriacylglycerolemia: historical perspective and review of biological mechanisms. Am J Clin Nutr. 2000;71:412-33.

67. Rudkowska I, Paradis A-M, Thifault E, Julien P, Tchernof A, Couture P, Lemieux S, Barbier O, Vohl M-C. Transcriptomic and metabolomic signatures of an n-3 polyunsaturated fatty acids supplementation in a normolipidemic/normocholesterolemic Caucasian population. The Journal of Nutritional Biochemistry. 2013;24:54-61.

68. van Breda SGJ, Wilms LC, Gaj S, Jennen DGJ, Briedé JJ, Helsper JP, Kleinjans JCS, de Kok TMCM. can transcriptomics provide insight into the chemopreventive mechanisms of complex mixtures of phytochemicals in humans? Antioxid Redox Signal. 2014;20:2107-13.

69. Nair AR, Mariappan N, Stull AJ, Francis J. Blueberry supplementation attenuates oxidative stress within monocytes and modulates immune cell levels in adults with metabolic syndrome: a randomized, double-blind, placebo-controlled trial. Food Funct. 2017;8:4118-28.

70. Ahmed M, Henson DA, Sanderson MC, Nieman DC, Gillitt ND, Lila MA. The protective effects of a polyphenolenriched protein powder on exercise-induced susceptibility to virus infection. Phytother Res. 2014;28:1829-36.

71. McAnulty LS, Collier SR, Landram MJ, Whittaker DS, Isaacs SE, Klemka JM, Cheek SL, Arms JC, McAnulty SR. Six weeks daily ingestion of whole blueberry powder increases natural killer cell counts and reduces arterial stiffness in sedentary males and females. Nutr Res. 2014;34:577-84.

Page 27/35 
72. Schisterman EF, Mumford SL, Sjaarda LA. Failure to Consider the Menstrual Cycle Phase May Cause Misinterpretation of Clinical and Research Findings of Cardiometabolic Biomarkers in Premenopausal Women. Epidemiol Rev. 2014;36:71-82.

73. Kawano H, Motoyama T, Kugiyama K, Hirashima O, Ohgushi M, Yoshimura M, Ogawa H, Okumura K, Yasue H. Menstrual cyclic variation of endothelium-dependent vasodilation of the brachial artery: possible role of estrogen and nitric oxide. Proceedings of the Association of American Physicians. 1996;108:473-80.

74. Serafini M, Testa MF, Villaño D, Pecorari M, van Wieren K, Azzini E, Brambilla A, Maiani G. Antioxidant activity of blueberry fruit is impaired by association with milk. Free Radic Biol Med. 2009;46:769-74.

75. Michalska A, Łysiak G. Bioactive compounds of blueberries: post-harvest factors influencing the nutritional value of products. Int J Mol Sci. 2015;16:18642-63.

76. Nemzer B, Vargas L, Xia X, Sintara M, Feng H. Phytochemical and physical properties of blueberries, tart cherries, strawberries, and cranberries as affected by different drying methods. Food Chem. 2018;262:242-50.

\section{Figures}

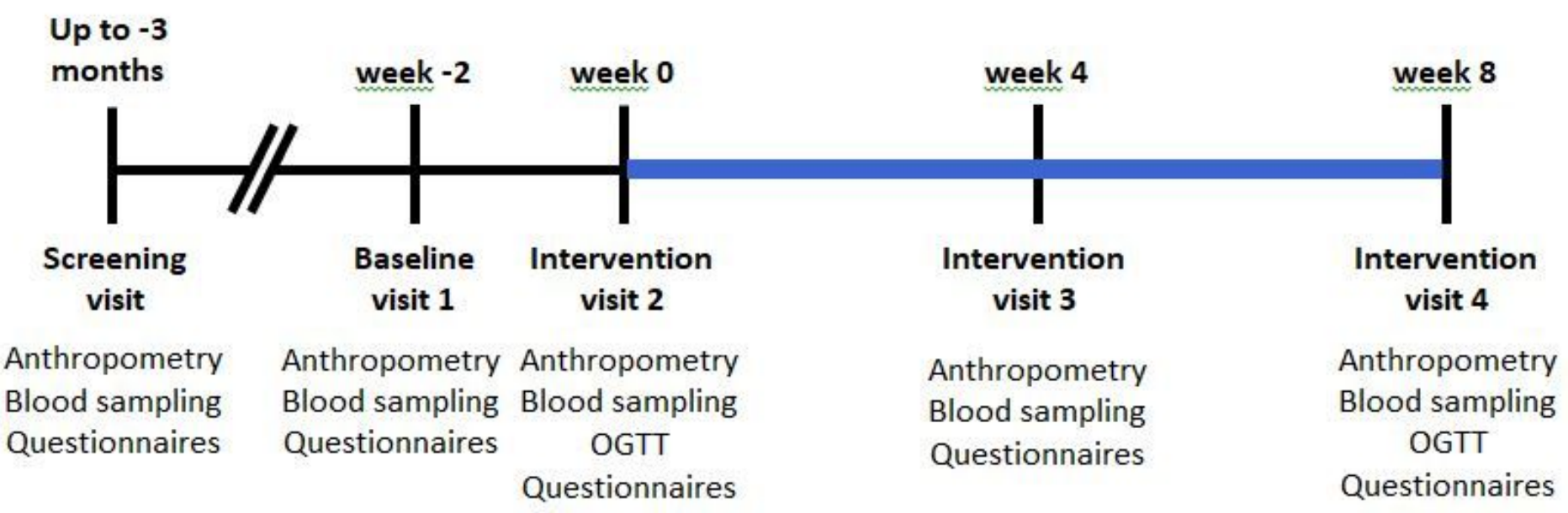

Figure 1

Graphical representation of the study protocol. Study design graphical representation from recruitment to the end of the supplementation period. The blue line represents the intervention period. Abbreviation: OGTT: Oral glucose tolerance test 


\section{O N S O R T \\ TRANSPARENT REPORTING of TRIALS}

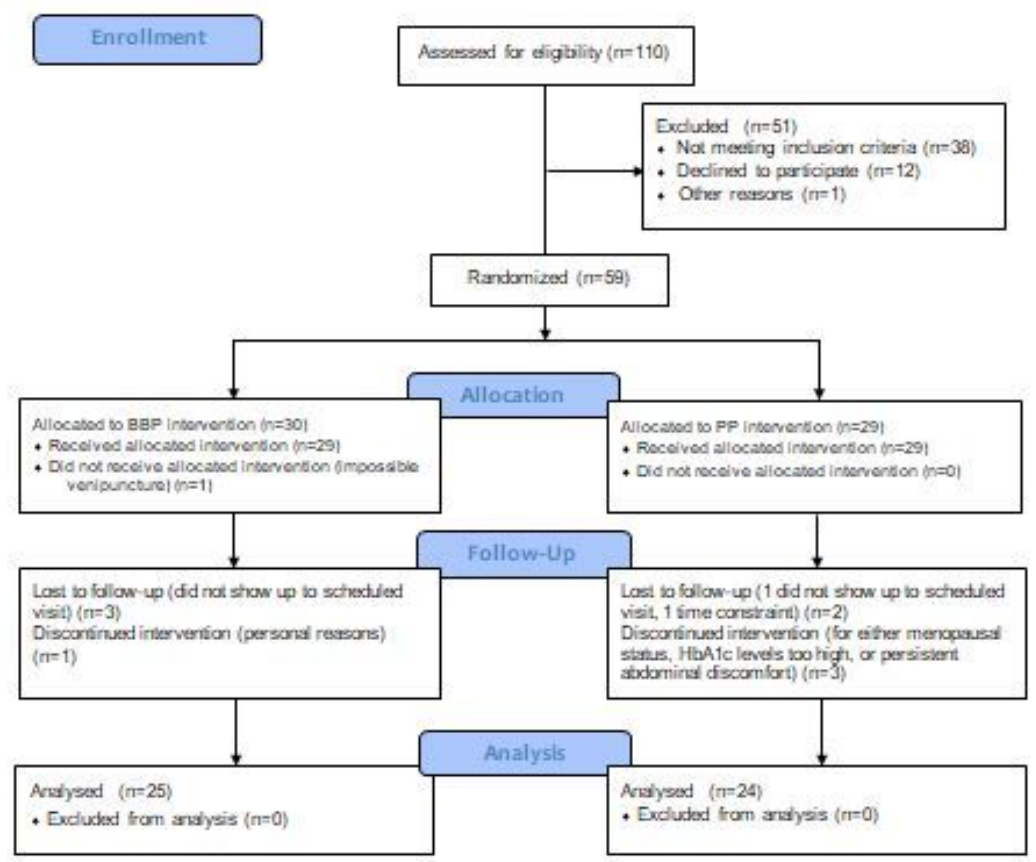

Figure 2

CONSORT 2010 Flow Diagram 


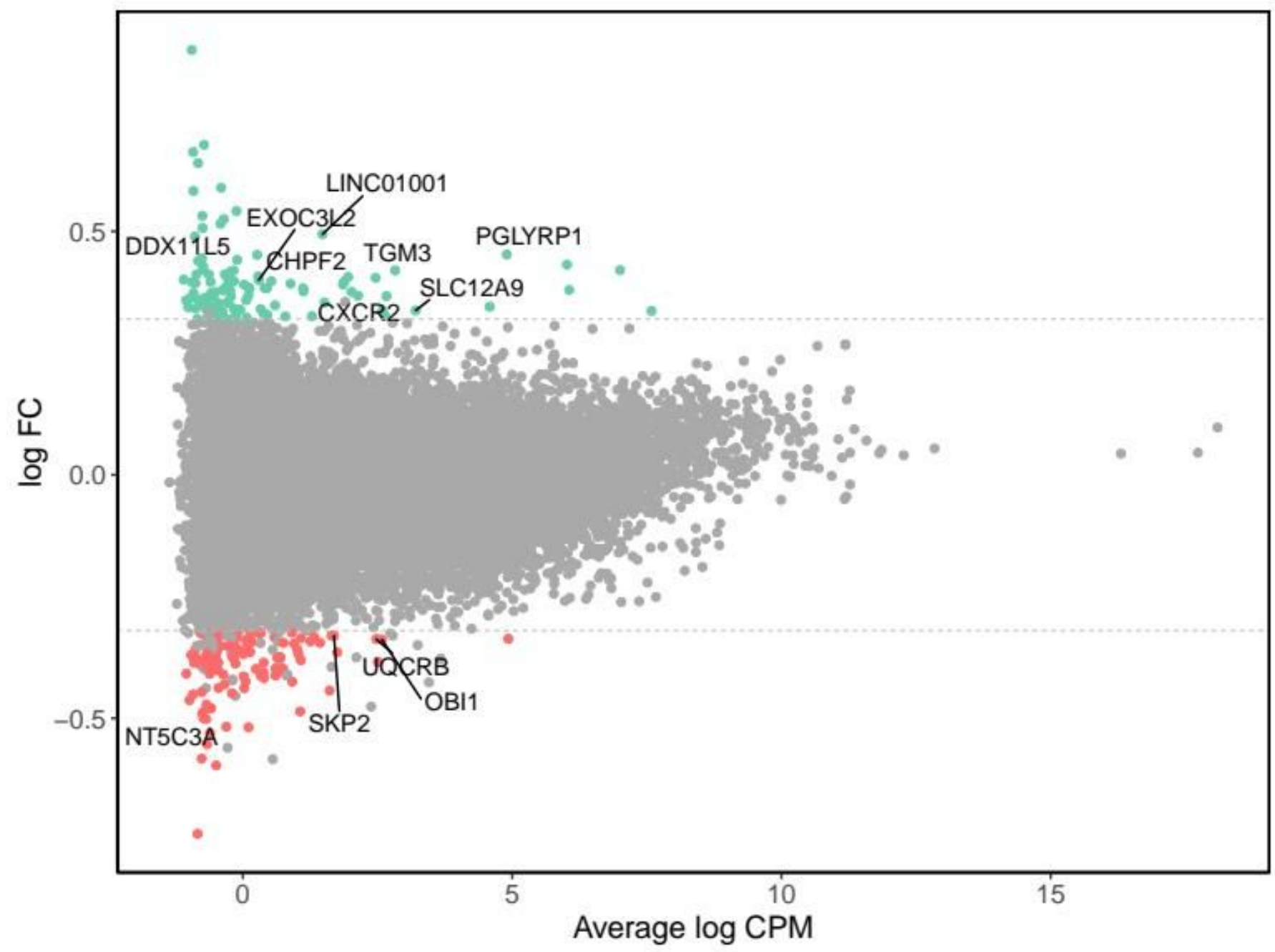

\section{Figure 3}

Global gene expression change between pre- and post-supplementation states in the blueberry group. MA plot shows the log2 average abundance of transcripts in counts per million mapped reads (log CPM) on the x-axis and the log2fold change (log FC) on the y-axis. Non-significant genes are represented by grey dots. Over-and under-expressed genes ( $F C>1.25)$ with unadjusted significant differences (paired t-test $p$-value $<0.05$ ) are coloured in green and red, respectively. Significant differentially expressed genes from paired t-tests (FDR-adjusted p-value<0.05) and showing at least a 1.25 FC are labelled with gene names. The dashed lines represent 1.25 FC. 


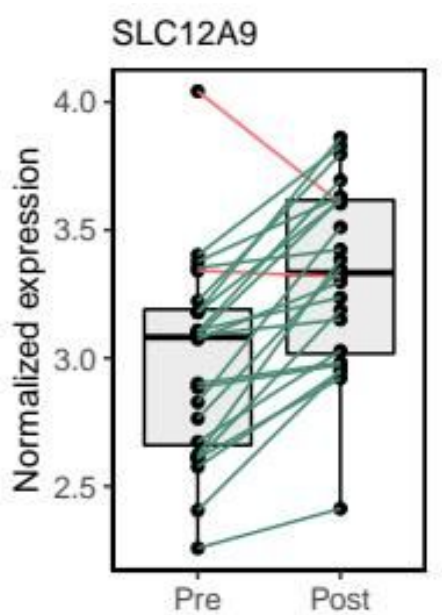

TGM3
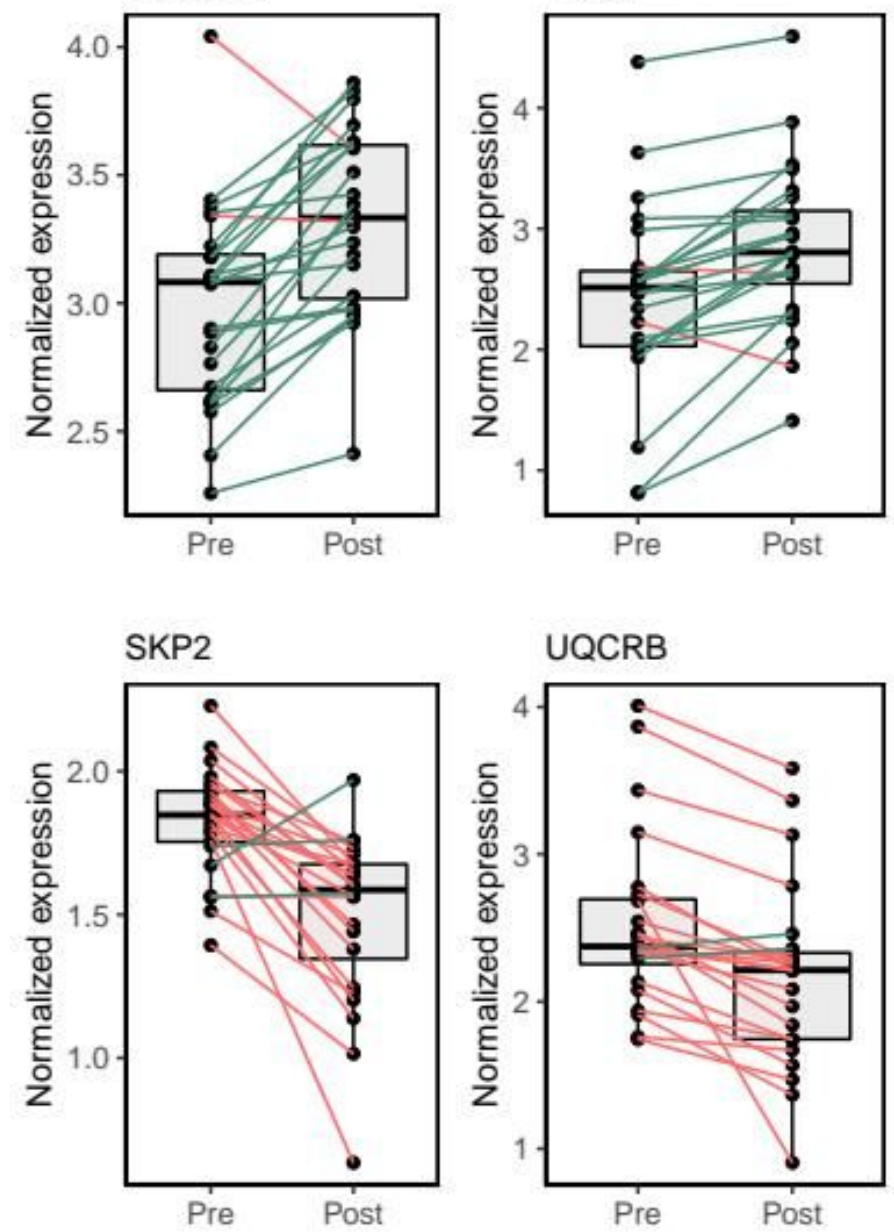

\section{EXOC3L2}
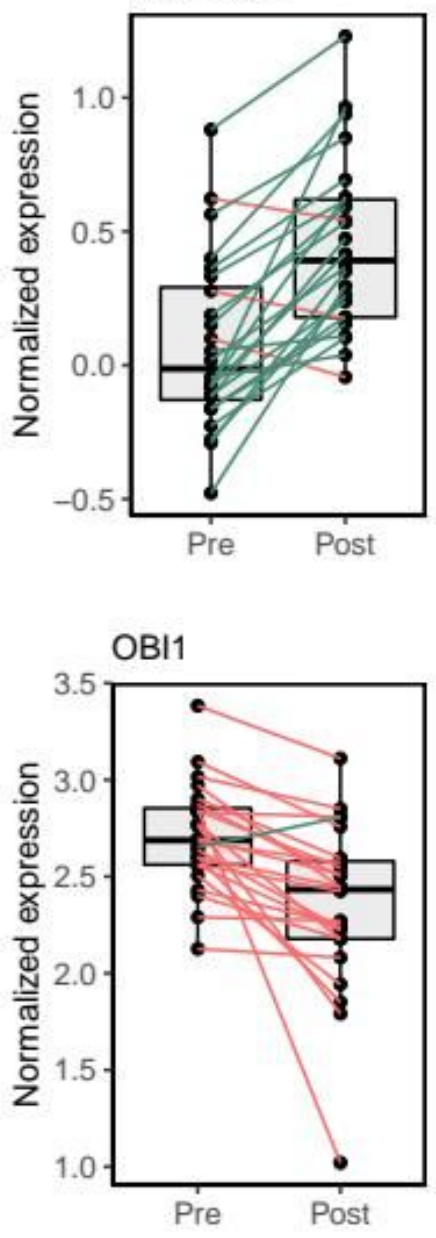

\section{Figure 4}

Top differentially expressed genes between pre- and post-supplementation states in the blueberry group. Box and whisker plots show median, first, and third quartiles, and maximum and minimum values for the 24 sample pairs before (Pre) and after (Post) the blueberry supplementation. The three transcripts which exhibited the most significant (FDR-adjusted p-value<0.05) over- and under-expression derived from paired t-tests (Post vs Pre) are shown on the top and bottom rows, respectively. Green and red lines stand for increasing or decreasing gene expression levels between pre- and post-supplementation states within individual paired samples. 


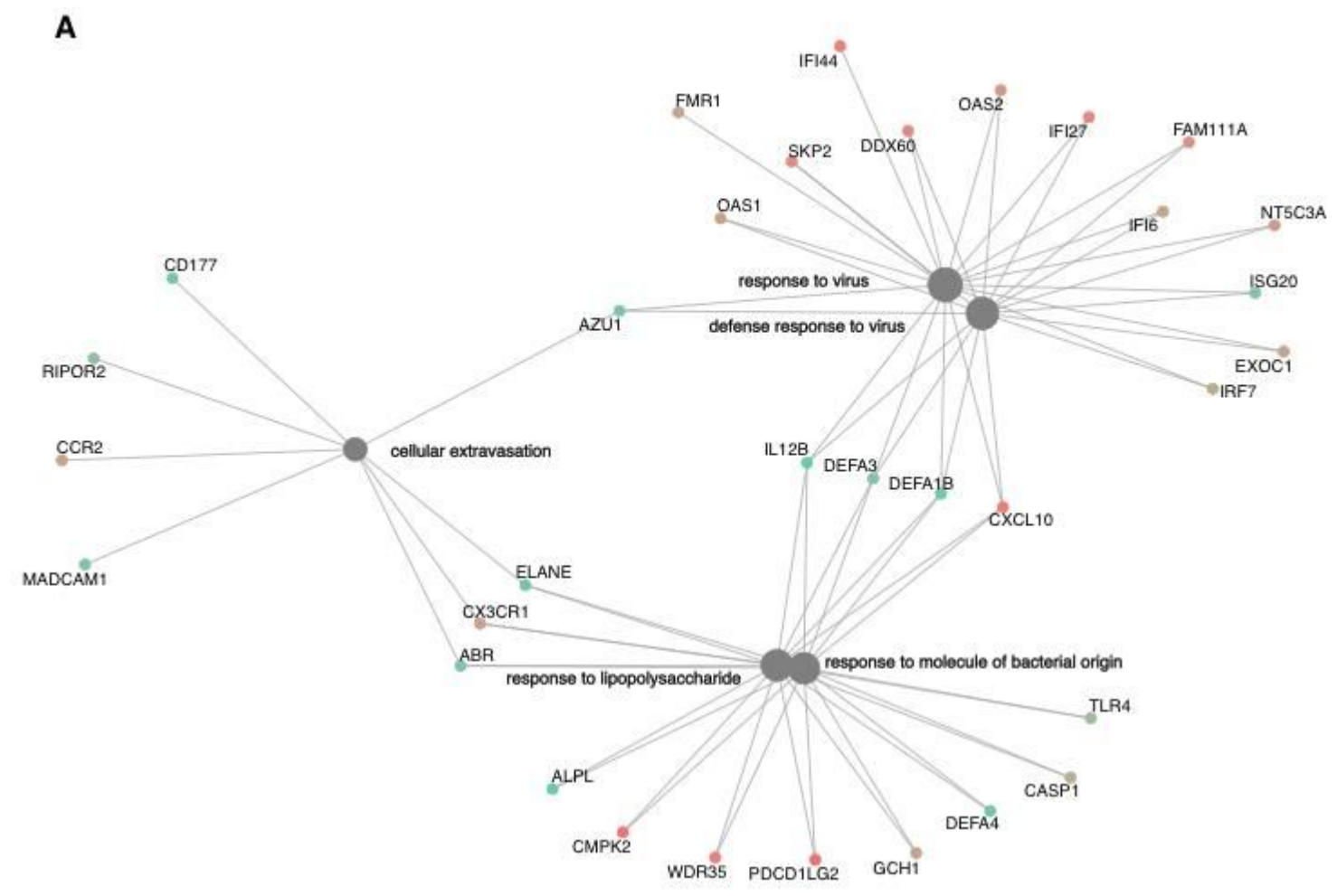

B

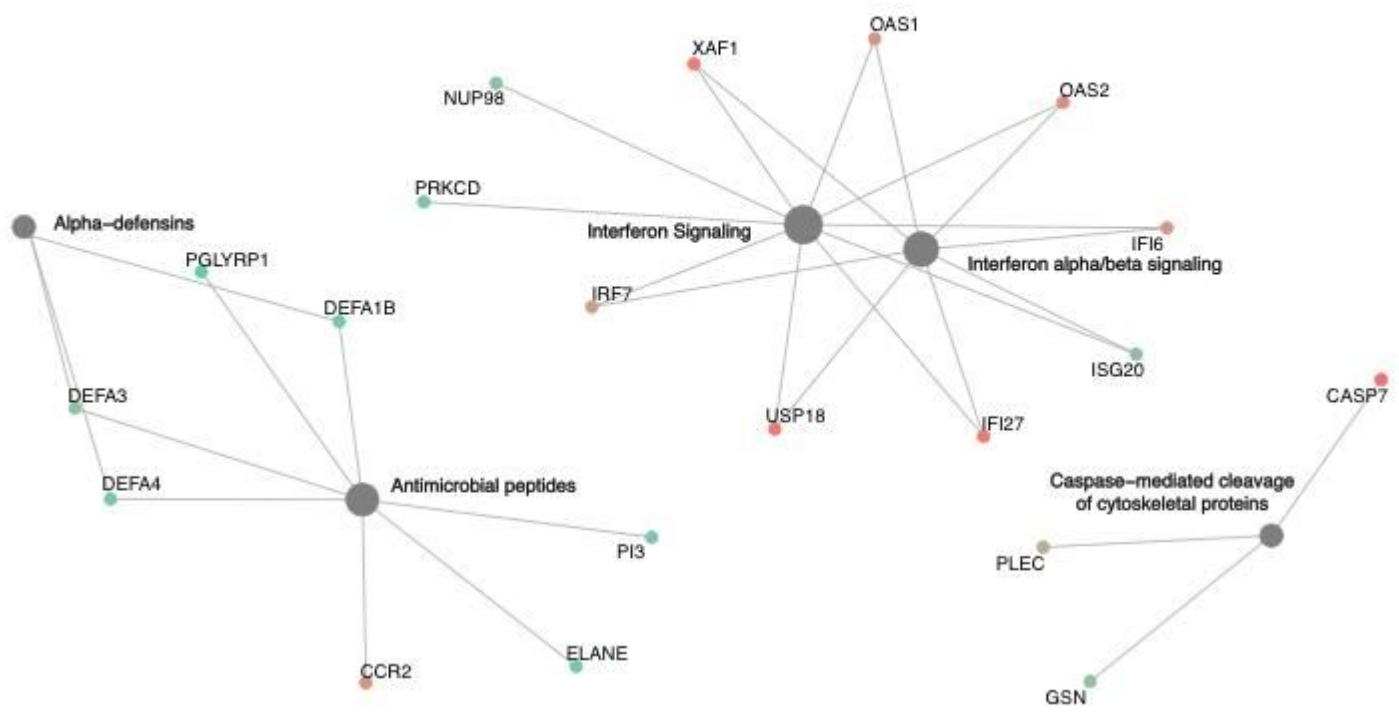

Figure 5

Network plots of enriched terms following the blueberry supplementation. The network plot depicts the linkages among differentially expressed gene clusters and functional enriched terms in the Gene Ontology Biological Processes (GO-BP) (A) and Reactome (B) pathway databases. The size of the grey dots is proportional to the number of genes in the enriched pathway (from 3 to 16) and the red-to-green color gradient of gene dots represents the direction of the gene expression fold change following the blueberry supplementation from down- to up-regulation, respectively. 


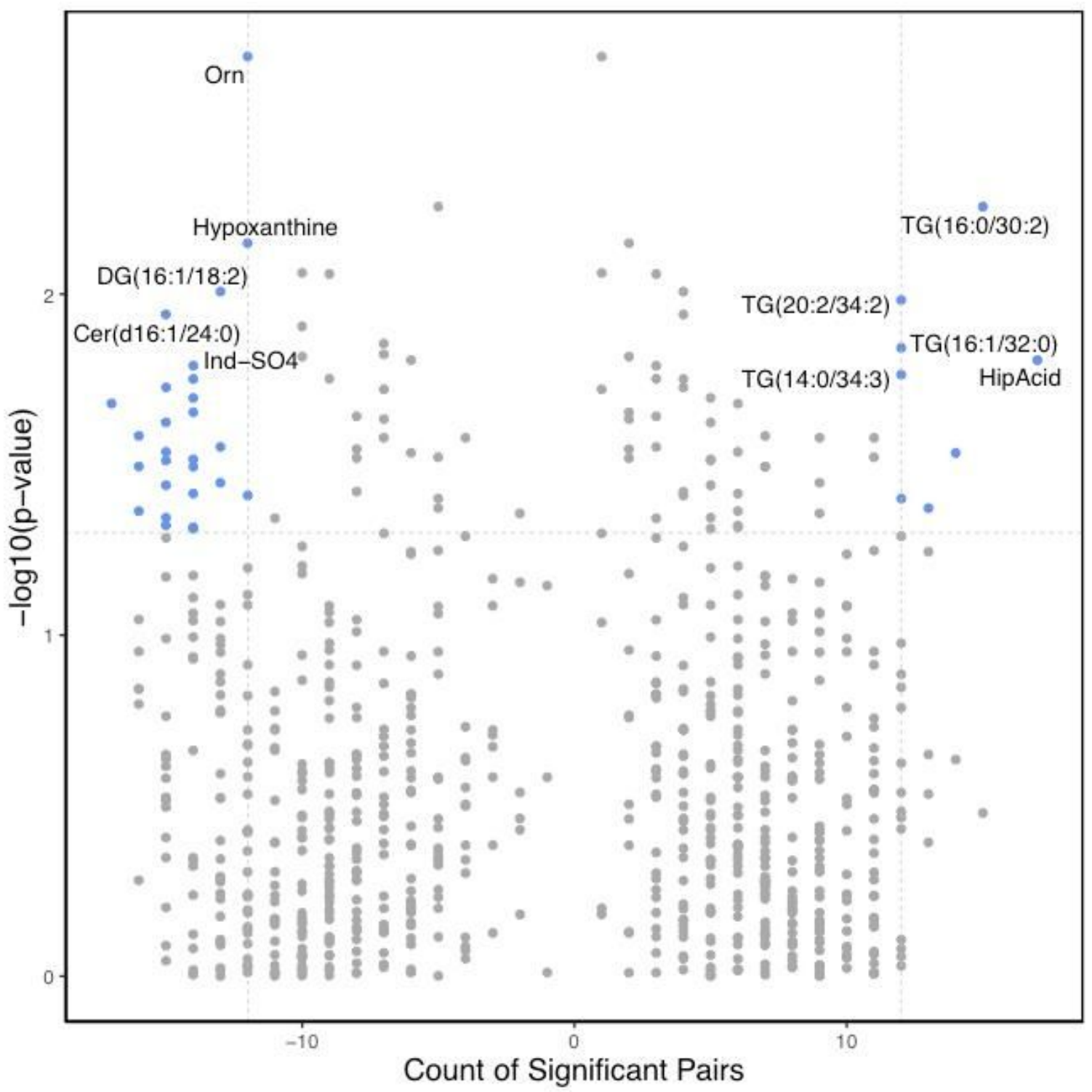

Figure 6

Impact of BBP supplementation on blood metabolite levels. Volcano plot of paired comparisons between metabolite blood levels in pre- and post-supplementation groups. On the x-axis, a count of significant sample pairs is shown. On the $y$-axis, the minus logarithm of paired t-test p-values is shown. Blood levels of a given metabolite were considered significantly different between pre- and post-supplementation states when the paired t-test p-value was $<0.05$, the change in metabolite blood levels was higher than $25 \%$ (>1.25-fold change), and the count of significant pairs was higher than the $50 \%$ of the total count of pairs. Each dot represents a metabolite. Metabolites showing statistically significant changes following the blueberry supplementation are depicted as blue dots on the right (increase) and left (decrease) top corners. Top-ten significantly different metabolites are labelled. Orn: ornithine, DG: diacylglycerol, Cer: ceramide, Ind-SO4: indoxyl sulfate, TG: triglyceride, HipAcid: hippuric acid. 

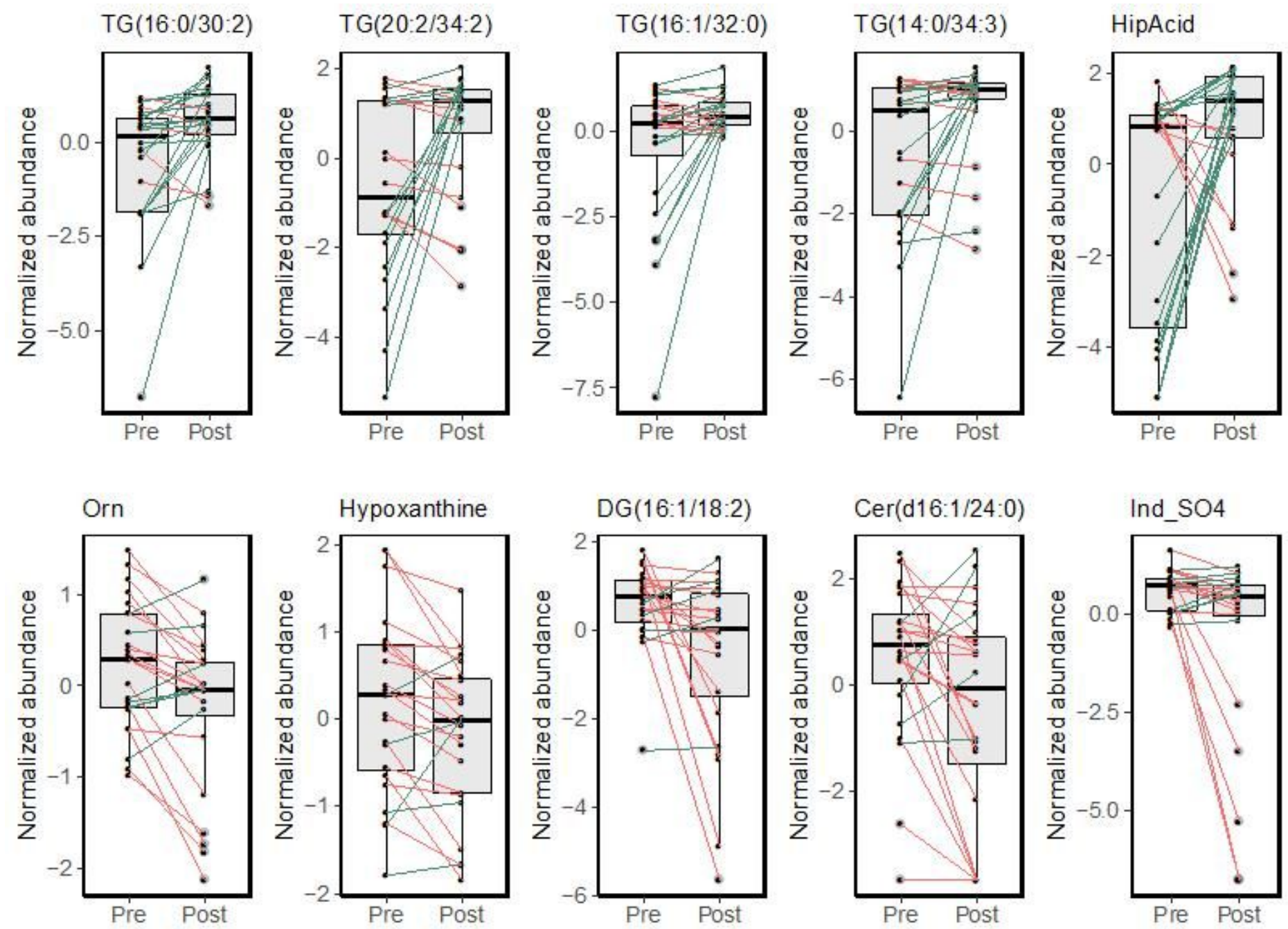

Figure 7

Top metabolites showing significant changes following BBP supplementation. Box and whisker plots show median, first, and third quartiles, and maximum and minimum values for the 24 sample pairs before (Pre) and after (Post) the blueberry supplementation. The five metabolites which exhibited the most significant decrease and increase following the supplementation are shown on the top and bottom rows, respectively. Green and red lines stand for increasing or decreasing metabolite blood levels between pre- and post-supplementation states within individual paired samples. Orn: ornithine, DG: diacylglycerol, Cer: ceramide, Ind-SO4: indoxyl sulfate, TG: triglyceride, HipAcid: hippuric acid. 

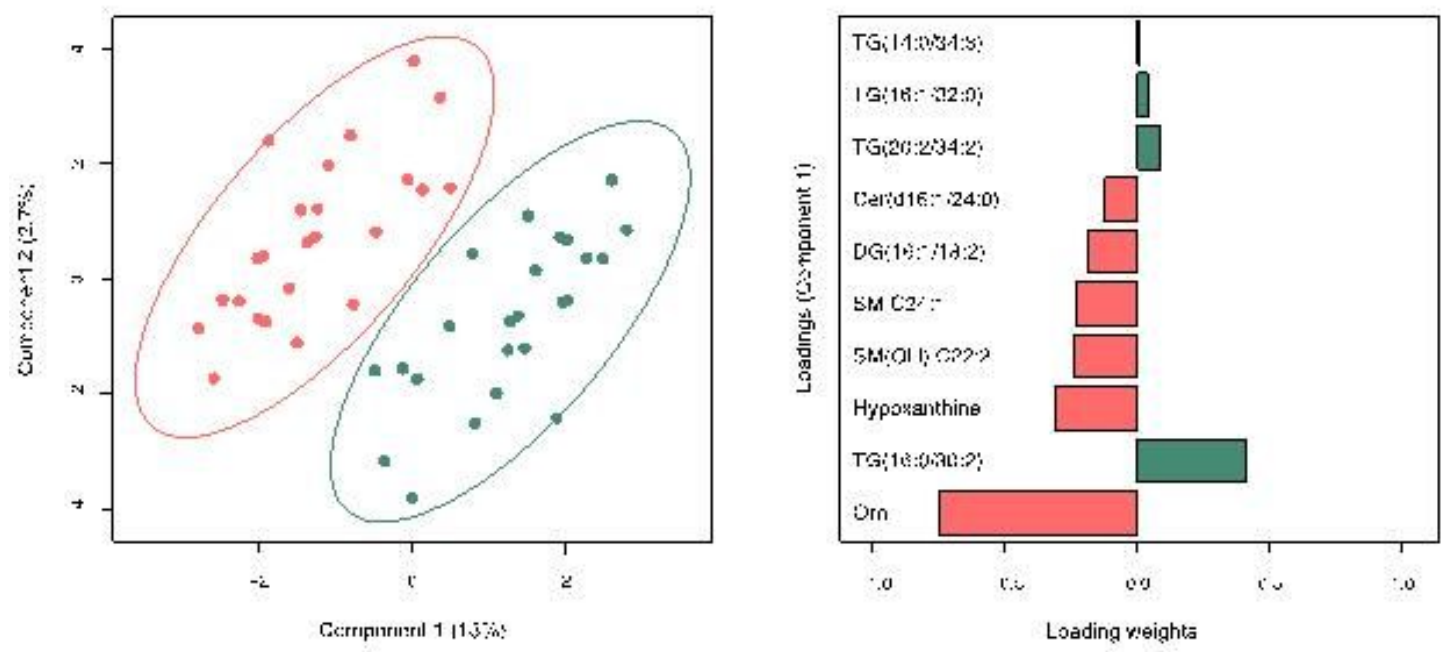

\section{Figure 8}

Identification of metabolites using Sparse Multilevel Partial Least Squares-Discriminant Analysis (smPLS-DA). A bidimensional score plot is shown on the left panel. The score plot reveals the distinct blood metabolomic profile between pre- (red dots) and post-supplementation (green dots) paired participants. The two principal components of the smPLS-DA model along with their corresponding variance in group discrimination are shown on $y$-and $x$-axis, respectively. The loading plot representing the top 10 metabolites selected on the first component of the smPLS-DA model is shown on the right. Horizontal bars represent the loading weights of each metabolite. Most important metabolites in group discrimination are ordered according to their loading weights, from bottom to top. Bar colour indicates the group for which the mean value is the highest for each feature (orange and green stand for pre- and postsupplementation groups, respectively). TG: triglyceride, Cer: ceramide, DG: diacylglycerol, SM: sphingolipid, Orn: ornithine. 